University of New Hampshire

University of New Hampshire Scholars' Repository

Master's Theses and Capstones

Student Scholarship

Winter 2016

\title{
INTERANNUAL VARIABILITY OF MIXED LAYER DYNAMICS IN THE ECUADORIAN OCEAN
}

Maria Jose Marin Jarrin

University of New Hampshire, Durham

Follow this and additional works at: https://scholars.unh.edu/thesis

\section{Recommended Citation}

Marin Jarrin, Maria Jose, "INTERANNUAL VARIABILITY OF MIXED LAYER DYNAMICS IN THE ECUADORIAN OCEAN" (2016). Master's Theses and Capstones. 890.

https://scholars.unh.edu/thesis/890

This Thesis is brought to you for free and open access by the Student Scholarship at University of New Hampshire Scholars' Repository. It has been accepted for inclusion in Master's Theses and Capstones by an authorized administrator of University of New Hampshire Scholars' Repository. For more information, please contact Scholarly.Communication@unh.edu. 


\title{
INTERANNUAL VARIABILITY OF MIXED LAYER DYNAMICS IN THE ECUADORIAN OCEAN
}

\author{
BY \\ MARÍA JOSÉ MARIN JARRIN \\ B.Sc. in Oceanography, ESPOL, 2009.
}

\section{THESIS}

Submitted to the University of New Hampshire

In Partial Fulfillment of

The Requirements for the Degree of

Master of Science

In

Earth Science - Oceanography

December, 2016 
This thesis dissertation has been examined and approved in partial fulfillment of the requirements for the degree of $\mathrm{M}$. Sc. in Earth Sciences - Oceanography by:

Thesis Director, Thomas C. Lippmann,

Associate Professor of Earth Science, Ph. D.

James M. Pringle,

Associate Professor of Earth Science, Ph. D.

Douglas C. Vandemark,

Research Professor, Ph. D.

On September $2^{\text {nd }}, 2016$

Original approval signatures are on file with the University of New Hampshire Graduate School. 


\section{ACKNOWLEDGEMENTS}

This Master's program was funded through a Scholarship from the Secretary of Higher Education, Science, Technology and Innovation of the Republic of Ecuador. Additional funding was provided by the University of New Hampshire's Graduate School, the School of Marine Sciences as well as the Oceanography program.

The different oceanographic research programs have been funded in each Institution through Government funding, as well as international agreement cooperation. The two long coastal stations data sets (La Libertad and Manta) have been obtained from the Ocean Sciences' department in the Oceanographic Institute of the Navy of Ecuador. Special thanks to each and every individual who surveyed the stations, cooperated in the logistics of those or have looked into the time series. The three shorter records from Esmeraldas, Puerto López and Salinas have been obtained from different programs in the National Fisheries Institute of Ecuador. Special thanks to the oceanographers, as well as the fishermen who cooperated in obtaining data from these important areas.

This work is dedicated to my family and friends who have supported me and helped me throughout these years, whom I love and give thanks for their incredible presence in my life.

"Suyo es el mar, pues Él lo hizo, Y la tierra firme que modelaron sus manos" 


\section{TABLE OF CONTENTS}

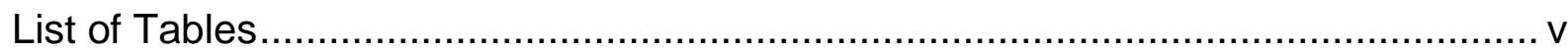

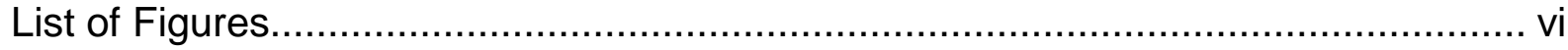

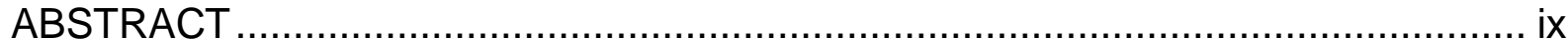

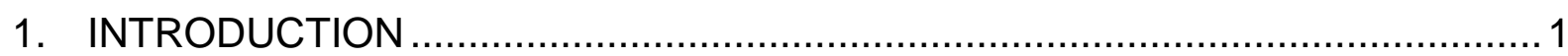

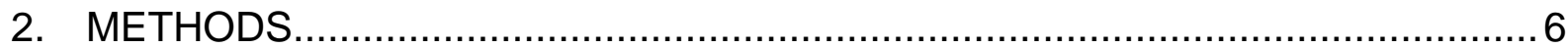

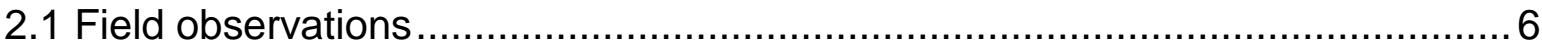

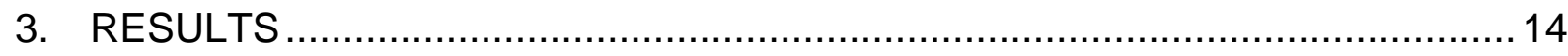

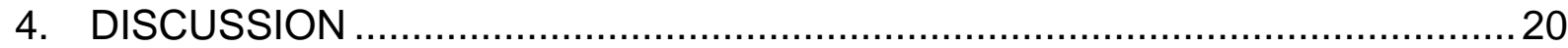

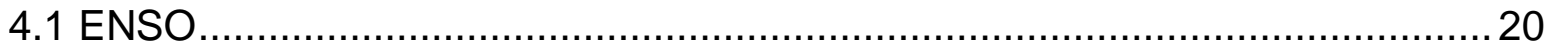

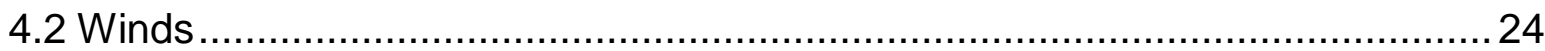

4.2 Potential sources of uncertainty in the analyses .......................................28

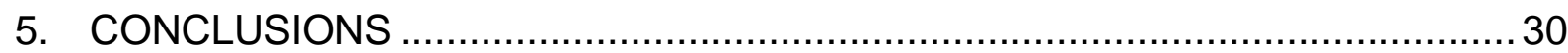

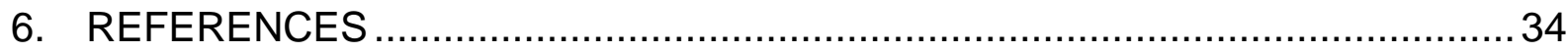

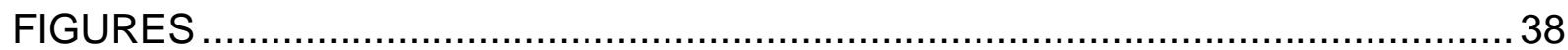




\section{List of Tables}

Table 1. Location (fraction degrees), dates, number of samples, and monthly temperature $\left({ }^{\circ} \mathrm{C}\right)$ maxima, minima, and standard deviation from coastal oceanographic stations and TAO buoys....................................................... 5

Table 2. Maxima, minima and standard deviation of mixed Layer depth, depth of $20^{\circ} \mathrm{C}$ isotherm and heat content from the coastal stations and TAO buoys................ 13

Table 3. Cross-correlations between EOF amplitude time series from coastal stations and TAO buoys. Significance levels in parenthesis as determined by Ebisuzaki (1997).

Table 4. Cross-correlations between the coastal stations (CS) and TAO buoys with ENSO SST 3.4 and $1+2$ region indices. 95\% significance levels are given in parenthesis (determined by Ebisuzaki (1997). Numbers in bold are significant). 23 


\section{List of Figures}

Fig. 1. Upper panel: GEBCO topography/bathymetry of the study area. Coastal stations are shown in red circles, TAO buoys as white circles. Lower Panel: Bathymetric profile along the Equator with TAO buoys and coastal stations in red circles. 38

Fig. 2. Sea surface temperature climatology from AVHRR data spanning 1992-2015 from Reynolds, et al., (2009). The locations of coastal stations are shown in dark circles and TAO buoys in white circles. 39

Fig. 3. Surface Salinity Climatology (Aquarius data set from 2011/09 - 2015/05). The locations of coastal stations and TAO buoys are shown in dark circles. 40

Fig. 4. T/S diagrams for the coastal station data. Panels are ordered by latitude with North upwards. Also shown are T/S signatures for Tropical and Subtropical Surface Waters (from Cucalón 1983). Colors represent depth (scale bar shown on the right).

Fig. 5. Time series of sea temperature profiles from 0 to $100 \mathrm{~m}$ of depth at the 5 coastal stations. Panels are ordered by latitude with North upwards. The depth of the $20^{\circ} \mathrm{C}$ isotherm is contoured in black.

42

Fig. 6. Temperature profile climatology from coastal stations. Panels are ordered by latitude with North upwards. $20^{\circ} \mathrm{C}$ isotherm in white contours.

Fig. 7. Heat Content, $20^{\circ} \mathrm{C}$ isotherm depth and mixed layer depth from each coastal station. Missing data are due to profiles that do not extend to depths of $100 \mathrm{~m}$, where the MLD or $20^{\circ} \mathrm{C}$ contour is greater than $100 \mathrm{~m}$, or there is no salinity data. Black squares on top denote warm events and gray squares denote cold events, based on 3 month running mean of ERSST.v4 SST anomalies in the Niño 3.4 region.

Fig. 8. T/S diagrams for the TAO buoy data. Panels are ordered by latitude with North upwards. Also shown are T/S signatures for Tropical and Subtropical Surface Waters (from Cucalón 1983). Colors represent depth (scale bar shown on the right).

Fig. 9. Time series of sea temperature profiles from 0 to $100 \mathrm{~m}$ of depth at the 3 TAO buoys. Panels are ordered by latitude with North upwards. The depth of the $20^{\circ} \mathrm{C}$ isotherm is contoured in black. Profiles have been linearly interpolated from standard depths to an evenly spaced grid with $1 \mathrm{~m}$ resolution. 46

Fig. 10. Temperature profile climatology from TAO buoys. Panels are ordered by latitude with North upwards. $20^{\circ} \mathrm{C}$ isotherm in white contours. 47

Fig. 11. Heat Content, $20^{\circ} \mathrm{C}$ isotherm depth and mixed layer depth from each TAO buoy. Missing data are due to profiles that do not extend to depths of $100 \mathrm{~m}$, where the MLD or $20^{\circ} \mathrm{C}$ contour is greater than $100 \mathrm{~m}$, or there is no salinity data. Black squares on top denote warm events and gray squares denote cold events, based on 3 month running mean of ERSST.v4 SST anomalies in the Niño 3.4 region. 48 
Fig. 12. Left panels: First 3 spatial EOF modes from analysis of temperature anomaly coastal station data at La Libertad and Manta (long records). EOF's are shown as a function of depth and latitude, and are normalized to have a maximum absolute value of 1. Right panels: The corresponding EOF amplitude time series for the first 3 modes. The amplitudes correspond to the largest temperature anomaly of each profile. The fraction of variance explained by each mode is shown on each panel. Black squares on top denote warm events and gray squares denote cold events, based on 3 month running mean of ERSST.v4 SST anomalies in the Niño 3.4 region. 49

Fig. 13. Left panels: First 3 spatial EOF modes from analysis of temperature anomaly at all coastal stations data from 2004 to 2014 (length of shorter records). EOF's are shown as a function of depth and latitude, and are normalized to have a maximum absolute value of 1 . Right panels: The corresponding EOF amplitude time series for the first 3 modes. The amplitudes correspond to the largest temperature anomaly of each profile. The fraction of variance explained by each mode is shown on each panel. Black squares on top denote warm events and gray squares denote cold events, based on 3 month running mean of ERSST.v4 SST anomalies in the Niño 3.4 region. 50

Fig. 14. Left panels: Comparison of EOF amplitude time series from the analysis of the short (red) and long (blue) records. Right panels: Cross-correlation between EOF 1,2 and 3 from the long record analysis with EOF 1, 2 and 3 from the short record analysis. 95\% confidence intervals were determined by method described in Ebisuzaki (1997). 51

Fig. 15. Left panels: First 3 spatial EOF modes from analysis of temperature anomaly at all TAO buoys. EOF's are shown as a function of depth and latitude, and are normalized to have a maximum absolute value of 1. Right panels: The corresponding EOF amplitude time series for the first 3 modes. The amplitudes correspond to the largest temperature anomaly of each profile. The fraction of variance explained by each mode is shown on each panel. Black squares on top denote warm events and gray squares denote cold events, based on 3 month running mean of ERSST.v4 SST anomalies in the Niño 3.4 region. ...................52

Fig. 16. Left panels: Comparison of EOF amplitude time series from the analysis of the coastal stations (long record in blue) and TAO buoy (red) data. Right panels: Cross-correlation between EOF 1, 2 and 3 from the long record analysis with EOF 1,2 and 3 from the TAO buoy data analysis. 95\% confidence intervals were determined by method described in Ebisuzaki (1997). 53

Fig. 17. Graphical depiction of the four Niño regions: Niño-1+2 $\left(0-10^{\circ} \mathrm{S}, 90^{\circ} \mathrm{W}-80^{\circ}\right.$ $\mathrm{W})$, Niño $3\left(5^{\circ} \mathrm{N}-5^{\circ} \mathrm{S}, 150^{\circ} \mathrm{W}-90^{\circ} \mathrm{W}\right)$, Niño $4\left(5^{\circ} \mathrm{N}-5^{\circ} \mathrm{S}, 160^{\circ} \mathrm{E}-150^{\circ} \mathrm{W}\right)$ and Niño - $3.4\left(5^{\circ} \mathrm{N}-5^{\circ} \mathrm{S}, 170^{\circ} \mathrm{W}-120^{\circ} \mathrm{W}\right)$. (Rasmusson and Carpenter 1982).

54

Fig. 18. Time series of ENSO $1+2$ and 3.4 regions from ERSST.v4 SST anomalies in the Niño 3.4 region $\left(5^{\circ} \mathrm{N}-5^{\circ} \mathrm{S}, 120^{\circ}-170^{\circ} \mathrm{W}\right)$ and Niño $1+2\left(0-10^{\circ} \mathrm{S}, 90^{\circ} \mathrm{W}-\right.$ $80^{\circ} \mathrm{W}$ ) (Huang et al. 2015). 55 
Fig. 19. Top panels: Mixed layer depth and depth of the $20^{\circ} \mathrm{C}$ isotherm at the coastal stations (blue) and TAO buoys (red) separated by Niño (warm), normal and Niña (cold) events. Error bars are calculated from one standard deviation. Lower panels: Heat Content and Amplitude of the First EOF mode at the coastal stations (blue) and TAO buoys (red). Error bars are calculated from one standard deviation separated by Niño (warm), normal and Niña (cold) events. 56

Fig. 20. Left panels: Comparison of EOF amplitude time series from analysis of anomaly coastal station data (long record in blue) with ENSO 1+2 (red) and ENSO 3.4 (green) indices. Right panels: Cross-correlations between coastal station amplitude EOF time series and ENSO 1+2 (blue) and 3.4 (red) indices. 95\% confidence intervals were determined by method described in Ebisuzaki (1997).

57

Fig. 21. Left panels: Comparison of EOF amplitude time series from analysis of anomaly TAO buoy data (blue) with ENSO 1+2 (red) and ENSO 3.4 (green) indices. Right panels: Cross-correlations between coastal station amplitude EOF time series and ENSO 1+2 (blue) and 3.4 (red) indices. 95\% confidence intervals were determined by method described in Ebisuzaki (1997). 58

Fig. 22. Cross-correlation between the coastal stations' first EOF mode and monthly averaged U (top panel) and V (lower panel) Winds obtained from ERA-Interim Reanalysis. Black squares denote the areas with largest (positive or negative) correlation, taken for EOF analysis. 59

Fig. 23. Left panels: First spatial EOF modes from analysis of Wind anomaly in the Colombian Basin and south of the Galápagos Islands (areas shown in Fig. 21). EOF's are shown as a function of longitude and latitude, and are normalized to have a maximum absolute value of 1 . Right panels: The corresponding EOF amplitude time series for the first EOF mode of Wind anomaly at the same area. The amplitudes correspond to the largest wind anomaly of each location. The fraction of variance explained by each mode is shown on each panel. Top (bottom) panels correspond to $\mathrm{U}(\mathrm{V})$ component of the wind.

Fig. 24. Left panels: Comparison of EOF amplitude time series from analysis of anomaly $U$ and $V$ winds at the Colombian Basin and south of the Galápagos Islands (black) with ENSO 1+2 (green) and ENSO 3.4 (magenta) indices. Right panels: Cross-correlations between the first mode of wind EOF time series and ENSO 1+2 (green) and 3.4 (magenta) indices. 95\% confidence intervals were determined by method described in Ebisuzaki (1997). 61 


\author{
ABSTRACT \\ INTERANNUAL VARIABILITY OF MIXED LAYER DYNAMICS \\ IN THE ECUADORIAN OCEAN \\ by \\ María José Marín Jarrín \\ University of New Hampshire, December, 2016.
}

Long time series spanning up to 22 years of monthly CTD profiles are used to examine upper water column ocean temperature interannual variability near the Ecuador coastline along the equator. The sampling program instituted by Ecuador's National Institute of Oceanography of the Navy (INOCAR) began in 1992 occupying two stations about $8 \mathrm{~nm}$ from the coast, and then expanding to an additional 3 stations in 2004 by Ecuador's National Fisheries Institute (INP) and National Institute of Meteorology and Hydrology (INAMHI). The stations are located near $80-81^{\circ} \mathrm{W}$ and extend from $2^{\circ} \mathrm{S}$ to $1^{\circ} \mathrm{N}$. Climatological (seasonal) signals are removed from the data to focus on the interannual variability. Characterizations of the anomaly time series include the $20^{\circ} \mathrm{C}$ isotherm depth, mixed layer depth (greater than $5 \mathrm{~m}$ depth), heat content (above $100 \mathrm{~m}$ ), and an EOF decomposition of the temperature profile data set. The data show marked interannual variations with distinct characteristics associated with ENSO indices that delineate periods of EI Niño, La Niña, and "normal" conditions. Heat content and the $20^{\circ} \mathrm{C}$ isotherm depth are both largest during El Niño periods, and weakest during La Niña periods. Mixed layer depths are largely invariant during the 
various periods, likely due to the dependence of the characterization on details of individual temperature profile. The first mode EOF decomposition of the anomaly long record coastal station data represents bulk variations $(71 \%)$ of the thermocline depth, and has temporal variability coupled $(R=0.65)$ to ENSO 3.4 and $1+2$ indices. Coastal observations are compared with temperature observations obtained over the same time period from the offshore TAO/Triton buoys located along $95^{\circ} \mathrm{W}$ from $2^{\circ} \mathrm{S}$ to $2^{\circ} \mathrm{N}$, to the west of the Galápagos Islands outside the geologic delineations of the Ecuadorian Sea. The EOF decomposition of TAO buoy anomaly time series shows similar spatial EOF structure, with the first mode representing bulk changes to the thermocline (about $71 \%$ of the variance). The first mode EOF amplitude time series from coastal and TAO station decomposition is correlated $(R=0.86)$, showing that the dominant variability of the upper water column thermal structure near the coast is coupled to variations along the equator and seaward of the Galápagos Islands. Comparisons of wind fields derived from ECMWF reanalysis in the regions shows that upwelling favorable winds to the north (in the Colombian basin) and to the south (along the coast of Perú) but away from the equator (where earth rotation impacts are minimal), produces a surface convergence at the equator close to shore that has variations that are strongly correlated with ENSO indices. The surface convergences are stronger during ENSO periods, and result in an increase in upper water column heating synchronous with the larger-scale ENSO variability. 


\section{INTRODUCTION}

The importance of interannual ocean variability in the far eastern equatorial Pacific has been widely known for its relationship to fish catch in Colombia, Ecuador, Perú and Chile [Glynn et al., 2001; Ballón et al., 2008; Bertrand et al., 2008; Deng et al., 2013]; however, the details of the dynamics are not fully understood. This is particularly evident along the Ecuadorian coast where complexity arises due to the influence of equatorial dynamics in the central Pacific, upwelling variability off the coast of Perú to the south, and eastward propagating equatorial-trapped Kelvin waves, all of which contribute to the variability in the upper water column, and are thus of great importance to the economic and social development of the country [CornejoRodríguez, 1987; Enfield et al., 1987; Lucero and Cornejo-Rodríguez, 1990; Enfield and Mestas-Nuñez, 2000].

The Ecuadorian Sea is located in the far eastern boundary of the equatorial Pacific, between the Galápagos triple junction and the South American plate, where the oceanic crust and lithosphere of the Nazca plate (Carnegie Ridge) begin their decent into the mantle beneath South America (Michaud et al. 2015; Fig. 1). The country of Ecuador is almost evenly divided by the equator, and thus occupies a somewhat unique position oceanographically where the Coriolis force goes to zero and changes sign. In general, the eastern equatorial Pacific is complex, with strong influences from circulation in the Colombian Basin at low northerly latitudes [VargasAngel et al., 2001], the Humboldt current to the south bringing lower surface ocean temperatures northward, periodically producing the "Cold Tongue" a result of coastal upwelling along the west coast of South America [Fiedler and Talley, 2006; Wade et 
al., 2011], and along the equator eastward propagating Kelvin waves [CornejoRodríguez, 1987; Cornejo-Rodríguez and Enfield, 1987] and the Equatorial Under Current (EUC; Fiedler and Talley 2006). This general complexity is evident in climatology of sea surface temperature (SST) derived from AVHRR satellite data (Reynolds 2009) near the Ecuadorian Sea (Fig. 2). Latitudinal gradients at the equator are present throughout the year, particularly strong during the first half of the calendar year, with much higher temperatures (up to $30^{\circ} \mathrm{C}$ ) at northern latitudes $\left(2-10^{\circ} \mathrm{N}\right.$ ) than in the south (about $22^{\circ} \mathrm{C} ; 2-10^{\circ} \mathrm{S}$ ). Between July and November, the influence of the Humboldt Current (northward flowing eastern boundary current extending the length of the South American continent) appears in the surface water properties in the southern part of the Ecuadorian Sea, bringing colder surface water (blue colors in Fig. 2) to the southern Ecuador coast.

Sea surface salinity climatology data (Fig. 3) from the IPRC/SOEST Aquarius satellite - obtained from the optimally interpolated sea surface salinity global dataset from 2011 to 2015 (Lee et al. 2012) - shows strong latitudinal variability throughout the year and the influence of southern waters during March-August, similar to what is observed in SST climatology. Additionally, the movement of the Inter Tropical Convergence Zone (ITCZ) which influences the variability of precipitation throughout the year (Huffman et al. 2007) and oceanography in the northern Tropical Atlantic [Fiedler and Talley, 2006; Lavín et al., 2006; Huffman et al., 2007], creates a less saline pool (about $30 \mathrm{PSU}$ ) around $96^{\circ} \mathrm{W}, 5^{\circ} \mathrm{N}$ close to the Isthmus of Panama [MoránTejeda et al., 2016]. This ocean-atmospheric teleconnection influences the Ecuadorian Sea contributing to a complex, biologically diverse and somewhat unique environment 
[Enfield and Mestas-Nuñez, 2000]. The dynamics are complicated by the presence of the Galápagos Islands and the submarine ridge along the equator (Fig. 1) connecting the islands to the mainland. Karnauskas et al. (2007) has suggested that properly including the Galápagos Islands in numerical models results in the obstruction of the EUC, as well as modifications in the simulated spatial structure of the Cold Tongue.

Surprisingly, few field studies have examined details of mixed layer dynamics in the Ecuadorian Sea, partially due to the lack of long term observations, including drifting buoys which travel away from the equator after approaching the Galápagos Islands (http://www.aoml.noaa.gov/phod/trinanes/xbt.html). However, since the recognition of the first effects of El Niño on the area [Wyrtki, 1975], Ecuador has developed programs to sample the water column $8 \mathrm{~nm}$ away from the coast (Fig. 1) using Conductivity-Temperature-Depth (CTD) profilers and water samples for chemical and biological properties, as well as installing coastal and inshore meteorological stations. Monthly CTD profiles (with sampling occurring on the third or fourth week of the month) have been obtained by three Ecuadorian Research Institutes: the National Institute of Oceanography of the Navy (INOCAR), the National Fisheries Institute (INP) and the National Institute of Meteorology and Hydrology (INAMHI) since 1992 (continuing today with international cooperative agreements amongst neighboring countries) at 5 different oceanographic stations (red circles in Fig. 1; Table 1). The sampling sites were established in 1992 by the 3 institutions, and located $8 \mathrm{~nm}$ from the coast for logistical convenience close to known productive fish-catch areas (http://cpps-int.org/). 
The purpose of this work is to evaluate the long time series of observations obtained at the Ecuadorian coastal stations, and to examine the interannual variability in the surface mixed layer hydrography observed near the Ecuador coast over the 22year record length. Owing to limitations in the observed salinity records and the generally small variation in upper ocean salinity of this area, temperature profiles will be primarily used to quantify surface layer variability. Analysis will be on anomaly time series whereby the climatological (seasonal) signal has been removed, and further be restricted to the upper $100 \mathrm{~m}$ of the water column due to typical CTD cast depths. Several parameters that characterize mixed layer variability will be computed, including the depth of the $20^{\circ} \mathrm{C}$ isotherm, mixed layer depth based on discrimination of the temperature profiles relative to a reference depth, integrated (over the vertical) heat content, and amplitude time series from dominant modes of an orthogonal decomposition (EOF) of the climatology-corrected (anomaly) data. We will examine the relationship between equatorial coastal ocean upper water column temperature variability with temperature profile time series observed to the west of the Galápagos Islands along the equator but outside the Ecuadorian Sea, EI Niño Southern Oscillation (ENSO) indices derived from satellite SST in the central Pacific, and regional winds derived from ECMWF reanalysis. 
Table 1. Location (fraction degrees), dates, number of samples, and monthly temperature $\left({ }^{\circ} \mathrm{C}\right)$ maxima, minima, and standard deviation from coastal oceanographic stations and TAO buoys.

\begin{tabular}{|c|c|c|c|c|c|c|c|}
\hline \multirow{2}{*}{$\begin{array}{l}\text { Name of } \\
\text { Station }\end{array}$} & \multirow{2}{*}{$\begin{array}{l}\text { Latitude } \\
\quad\left({ }^{\circ} \mathrm{N}\right)\end{array}$} & \multirow{2}{*}{$\begin{array}{c}\text { Longitude } \\
\left(^{\circ} E\right)\end{array}$} & \multirow{2}{*}{$\begin{array}{l}\text { Dates of } \\
\text { survey }\end{array}$} & \multirow{2}{*}{$\begin{array}{c}\text { Number } \\
\text { of data } \\
\text { sets }\end{array}$} & \multicolumn{2}{|c|}{$\begin{array}{c}\text { Temperature } \\
\text { Monthly Anomaly }\end{array}$} & \multirow{2}{*}{$\begin{array}{l}\text { Standard } \\
\text { Deviation }\end{array}$} \\
\hline & & & & & Max. & Min. & \\
\hline \multicolumn{8}{|c|}{ Monthly Coastal CTD stations } \\
\hline $\begin{array}{l}\text { Esmeraldas } \\
\text { (INP) }\end{array}$ & 1.08 & -79.74 & $\begin{array}{l}2004 \text { to } \\
2014\end{array}$ & 95 & 8.10 & -8.61 & 1.69 \\
\hline $\begin{array}{l}\text { Manta } \\
\text { (INOCAR) }\end{array}$ & -0.88 & -80.83 & $\begin{array}{l}1992 \text { to } \\
2014\end{array}$ & 219 & 9.57 & -7.87 & 1.89 \\
\hline $\begin{array}{l}\text { Puerto López } \\
\text { (INP) }\end{array}$ & -1.59 & -80.99 & $\begin{array}{l}2004 \text { to } \\
2014\end{array}$ & 90 & 4.48 & -5.20 & 1.28 \\
\hline $\begin{array}{l}\text { La Libertad } \\
\text { (INOCAR) }\end{array}$ & -2.07 & -81.12 & $\begin{array}{l}1992 \text { to } \\
2014\end{array}$ & 293 & 9.79 & -6.20 & 1.92 \\
\hline $\begin{array}{l}\text { Salinas } \\
\text { (INOCAR) }\end{array}$ & -2.12 & -81.13 & $\begin{array}{l}2004 \text { to } \\
2014\end{array}$ & 60 & 6.54 & -6.17 & 1.44 \\
\hline \multicolumn{8}{|c|}{ Daily TAO Project (NOAA/PMEL) buoys } \\
\hline TAO $2 \mathrm{~N}$ & 2.00 & -95.00 & $\begin{array}{c}1992 / 11- \\
2015 / 06\end{array}$ & 8248 & 12.55 & -6.99 & 1.71 \\
\hline TAO ON & 0.00 & -95.00 & $\begin{array}{l}1992 / 11- \\
2015 / 06\end{array}$ & 8257 & 11.52 & -5.89 & 1.76 \\
\hline TAO 2S & -2.00 & -95.00 & $\begin{array}{l}\text { 1992/11 - } \\
2015 / 04\end{array}$ & 8196 & 10.83 & -5.84 & 1.43 \\
\hline
\end{tabular}




\section{METHODS}

\subsection{Field observations}

\section{a. Coastal In-situ data}

Periodic sampling approximately $8 \mathrm{~nm}$ away from the coast was done using convenience vessels such as small fishing boats, pleasure craft, and Ecuadorian military ships. The SeaBird Electronics (SBE) CTD 19 and 19plus were used to obtain temperature and salinity depth profiles. Instruments were sent back to SBE about every two years for calibration. All CTD cast data were processed using software provided by SBE, filtered with a low-pass spatial filter, and further aligned relative to pressure (based on instrument response time). Data were not considered when the profiler was moving upwards. Temperature and salinity were averaged to evenly spaced $1 \mathrm{~m}$ depth bins using SBE's software. Profile data were further filtered with temperature/salinity (T/S) diagrams by manually eliminating those data points outside of the expected range (outliers) determined with a 3 standard deviation filter. Months with more than one sample were averaged, and all monthly samples at all stations were given a time stamp centered to the $15^{\text {th }}$ of each month. T/S data are shown in Fig. 4 with the depth of measurement indicated by the color of the data points. Most of the variability at the coastal stations occurs within a few meters of the surface (yellow colored dots), similar to characteristics of Tropical (TSW) and Subtropical Surface Waters (STSW), while the deeper waters (blue colored dots) have characteristics similar to Equatorial Subsurface Water (ESSW; Cucalón 1983). 
Time series of temperature profiles for each coastal station are shown in Fig. 5. Gaps in the data arise from poor CTD data, missed sampling times, or instrument malfunction. As expected the data reveal a clear seasonal variability with generally a deeper pool of surface warm water during the rainy season (April - August), similar to SST climatology (Fig. 2). Present also are longer time scale variations associated with (sometimes) strong interannual (or episodic) events. The $20^{\circ} \mathrm{C}$ isotherm, extensively used previously to characterize surface heating and cooling in the upper water column [Chavez et al., 1999; McPhaden, 2012] is indicated in the figure. During years of high surface heating (or reduced upwelling), the $20^{\circ} \mathrm{C}$ isotherm was not always present in the temperature profiles above $100 \mathrm{~m}$ (e.g., 1997-1998).

As an alternative, the surface layer variability can be parameterized by the thickness of the mixed layer depth (MLD), as suggested by Thomson and Fine (2003) and Jeronimo and Gomez-Valdes (2010). MLD was determined for each profile by searching for a temperature value differing by more than $0.5^{\circ} \mathrm{C}$ from the near-surface reference level, defined here as $5 \mathrm{~m}$ below the surface due to influence of high frequency variability right at the surface (following de Boyer Montégut et al. 2004). MLD depths less than $5 \mathrm{~m}$ and greater than $100 \mathrm{~m}$ could not be determined, and the possible presence of fossil thermoclines where noticed in the time series which contributed uncertainty in identifying a single representative MLD in any given profile.

A third method was considered based on heat content $\left(\mathrm{HC}\right.$; units of $\left.10^{10} \mathrm{~J} / \mathrm{m}^{2}\right)$, an often used proxy for the deepening or shallowing of the western Pacific thermocline depth [Wyrtki, 1981], defined by Dijkstra (2008) as 


$$
H_{C}=C_{p} \int_{-H_{f}}^{0} \rho T d z
$$

where $H_{f}$ is a fixed reference depth (chosen herein as $100 \mathrm{~m}$ due to the constraints of the observed temperature profiles), $\mathrm{Cp}$ is the heat capacity for seawater calculated using UNESCO 1983 polynomial formula, and $\rho$ is density of the water calculated using UNESCO 1983 (EOS 80) polynomial from observed temperature and salinity profiles (Fofonoff, et al. 1983). HC represents an integrated (over depth) value of total heat contained in the upper water column that is relatively insensitive to the shape of the temperature profile.

Monthly climatology was determined for temperature, salinity, and heat content by averaging all data for any given month over the 22-year record. Climatological monthly sea temperature profiles as a function of depth at the coastal stations (Fig. 6) show that from April to August most of the water column is warmer than the rest of the year, with a slight-apparent deepening of the $20^{\circ} \mathrm{C}$ isotherm (shown in white), quite similar to that observed in SST climatology (Fig. 2). The most southerly station (La Libertad at $2.03^{\circ} \mathrm{S}$, Table 1) shows a stronger influence of colder waters in August than that observed in Manta (located closer to the Equator at $0.86^{\circ} \mathrm{S}$, Table 1 ). The shorter-record stations (Esmeraldas, Puerto López and Salinas, located at $1.08^{\circ} \mathrm{N}$, $1.59^{\circ} \mathrm{S}$, and $2.12^{\circ} \mathrm{S}$; Table 1) show similar variability in time and depth; however, due (possibly) to the shorter record length (11 years; Table 1), the general climatology appears to be colder than stations with longer time series (22 years; Table 1). Despite the proximity to the coast, $\mathrm{HC}, \mathrm{MLD}$, and depth of the $20^{\circ} \mathrm{C}$ isotherm time series suggests that the coastal stations located $8 \mathrm{~nm}$ from the coast represent the general 
characteristics of the area without major influence by terrestrial freshwater runoff and river and outflow.

Our interests are in understanding the interannual variability that differs from the seasonal signal average. That is, we seek to identify the nature of the variability that differs from the climatology. To eliminate the seasonal cycle from the data, we subtract the climatology from the time series at each station, henceforth referred to as the "anomaly" time series.

Anomaly time series of the $20^{\circ} \mathrm{C}$ isotherm, MLD, and $\mathrm{HC}$ for all stations were determined by subtracting their respective climatology from the observations, and are subsequently used to assess the interannual variability of the upper water column (Fig. 7). Time series of the $20^{\circ} \mathrm{C}$ isotherm at Manta and La Libertad were quite similar, with depth ranges of $10-96 \mathrm{~m}$, and $6-93 \mathrm{~m}$, respectively (Table 2). The $20^{\circ} \mathrm{C}$ isotherm depth varied synchronously (0 lag) with temperature fluctuations at a depth of $5 \mathrm{~m}$ below the surface with correlations, $\mathrm{R}$, ranging $0.40-0.49$ for the long records (Manta and La Libertad) and $0.79-0.59$ at the shorter stations (Esmeraldas, Puerto López, and Salinas). MLD varied from $5-92 \mathrm{~m}$ at all the coastal stations, similar to the $20^{\circ} \mathrm{C}$ isotherm. MLD correlations with near-surface temperature (5 $\mathrm{m}$ depth) had weaker correlation ( $R=0.28-0.18)$ at the long-record stations (La Libertad and Manta), while the shorter records (Esmeraldas, Puerto López, and Salinas) have much higher correlation $(R=0.72-0.82)$. $\mathrm{HC}$ also shows strong interannual variability similar to the $20^{\circ} \mathrm{C}$ isotherm depth $(\mathrm{R}>0.27$ and $\mathrm{R}>0.65$ at the short and long records, respectively). In general, the $20^{\circ} \mathrm{C}$ isotherm depth and $\mathrm{HC}$ seem to follow each other 
reasonably closely, whereas the MLD time series has more variability, perhaps due to sensitivity of defining MLD on details of the salinity and temperature profiles.

\section{b. TAO buoy data}

Three surface and subsurface buoys from the Tropical Atmosphere Ocean Triangle Trans-Ocean Buoy Network (TAO/Triton) in the Pacific (data available from the TAO Project Office of NOAA/PMEL), west of the Galápagos at $95^{\circ} \mathrm{W}$, were used for comparison to the coastal stations (Table 1). Observations from TAO/Triton buoys included temperature at "standard depths" of $1,5,10,15,20,40,50,60,75,80$, and $100 \mathrm{~m}$, sea surface salinity, and winds (4 m above sea level). T/S data are shown in Fig. 8 using only times where water salinity measurements were available. Also shown are characteristic Tropical (TSW) and Subtropical Surface water (STSW), and Equatorial Subsurface Water (ESSW; Cucalón 1983). Given the large number of salinity dropouts [Chepurin and Carton, 1999], heat content here was obtained from data between depths ranging $1-100 \mathrm{~m}$ by using a constant salinity of 35 PSU over the water column (errors in $\mathrm{HC}$ using this assumption are negligible; Levitus et al. 2012). T/S values in Fig. 8 show that the TAO buoys have very similar characteristics to the coastal stations, where most of the variability occurs close to the surface, with similar characteristics to Tropical (TSW) and Subtropical Surface Waters (STSW), and deeper waters similar to Equatorial Subsurface Water (ESSW; Cucalón 1983).

Time series of temperature profiles from TAO buoys are shown in Fig. 9 over the same time period as the observations of the coastal station data (Fig. 6). As with the 
coastal data, there is a strong seasonal cycle with the same monthly pattern. The surface temperatures at the southern buoy are generally colder during the second half of the year than that observed in the northern buoy. TAO buoy climatological monthly sea temperature profiles as a function of depth (Fig. 10) show a slighter warming of the water from April to August compared to the coastal stations, with a slight-apparent deepening of the $20^{\circ} \mathrm{C}$ isotherm (shown in white) most noticeable in the equatorial and southern buoys. Stronger influence of cold waters beneath $80 \mathrm{~m}$ depth may be due to the influence of the EUC in waters west of the Galápagos Islands.

Fig. 11 shows the $20^{\circ} \mathrm{C}$ isotherm depth, MLD, and $\mathrm{HC}$ for each of the TAO buoys. The $20^{\circ} \mathrm{C}$ isotherm (in black contours in Fig. 9) at the $2^{\circ} \mathrm{N}$ buoy remains under $40 \mathrm{~m}$ depth, while at the other two buoys (at the Equator and $2^{\circ} \mathrm{S}$ ) this isotherm may reach up to $20 \mathrm{~m}$ depth during the second half of the year. $\mathrm{HC}$ time series were calculated using Equation (1) while accounting for the unequal depth locations of the instruments by linearly interpolating each profile to constant $1 \mathrm{~m}$ depth increments and density was determined by the temperature profiles and a constant salinity value observed at the surface. These time series qualitatively show similar behavior as the coastal stations (Fig. 11). Cross correlation between $\mathrm{HC}$ at the La Libertad coastal station and the TAO buoy data show most similarity with the southern buoy $(R>0.75)$ occurring at 0 lag, while at Manta, the maximum correlation with $T A O 2^{\circ} \mathrm{S}(\mathrm{R}=0.80)$ and $\mathrm{TAO} 0^{\circ} \mathrm{N}(\mathrm{R}=$ $0.68)$ occur at 1 -month lag, and at $\mathrm{TAO} 2^{\circ} \mathrm{N}(\mathrm{R}=0.72)$ occur at 0 lag. $\mathrm{HC}$ time series at the TAO buoys show qualitatively larger interannual and seasonal variations than MLD time series. MLD determination at the TAO buoys was more easily defined given 
that due to the interpolation of "standard depths", it was less likely to observe fossil thermoclines in the data set.

Analysis of surface layer variability using heat content, $20^{\circ} \mathrm{C}$ isotherm, or MLD analysis require predetermined parameters (e.g., depth limits, temperature value, or temperature range) making the results subject to somewhat arbitrary settings, often determined by limitations of the data sampling. To better objectively represent the surface layer variability measured by temperature profiles across all 5 coastal stations, the array time series, $X\left(\mathrm{x}_{m}, t\right)$, where $\mathrm{x}_{m}=f(x, z), \mathrm{x}$ is horizontal location of the stations, $\mathrm{z}$ is depth, and $\mathrm{t}$ is time, can be decomposed into an ordered set of $\mathrm{M}$ orthogonal functions (or EOF modes equal in number to the number of sampled locations in both horizontal and vertical dimensions) that span the variability in the most efficient manner, such that

$$
X\left(\mathrm{x}_{m}, t\right)=\sum_{j=1}^{M} A_{j}(t) F_{j}\left(\mathrm{x}_{m}\right)
$$

where $F_{j}\left(\mathrm{x}_{m}\right)$ are the normalized eigenvectors for mode $\mathrm{j}$, and the EOF amplitude time series (or temporal weighting), $A_{j}(t)$, are given by,

$$
A_{j}(t)=\sum_{m=1}^{M} F_{j}\left(\mathrm{x}_{m}\right) X\left(\mathrm{x}_{m}, t\right)
$$

The EOF modes are ordered in terms of the amount of variance explained with the first mode describing the highest fraction of variance. Physical interpretation of successively higher modes is difficult owing to the nature of the orthogonality constraints in the decomposition of the data. 
The two long record coastal stations (La Libertad and Manta) span 22 years, whereas the three short records (Esmeraldas, Puerto Lopez, and Salinas) span only 11 years. In order to encompass the longest time series and better evaluate the interannual variability, we will use the long record anomaly time series as our primary input to the EOF analysis. However, we will also compare the EOF decomposition from the long records with an EOF decomposition of all five stations but only for the overlapping portions (11 years). This allows and assessment of the impact that the spatial extent of the stations - larger for the short records and extending north of the equator - has on the interpretation of the results. We discuss the decomposition of the long records first, followed by the short record analysis.

Table 2. Maxima, minima and standard deviation of mixed Layer depth, depth of $20^{\circ} \mathrm{C}$ isotherm and heat content from the coastal stations and TAO buoys.

\begin{tabular}{|c|c|c|c|c|c|c|c|c|c|}
\hline \multirow{2}{*}{ Station } & \multicolumn{3}{|c|}{$\begin{array}{l}\text { Top of Mixed Layer } \\
\text { depth (m) }\end{array}$} & \multicolumn{3}{|c|}{$\begin{array}{c}\text { Depth of } 20^{\circ} \mathrm{C} \text { isotherm } \\
(\mathrm{m})\end{array}$} & \multicolumn{3}{|c|}{$\begin{array}{l}\text { Heat Content } \\
\left({ }^{*} 10^{9} \mathrm{~J} / \mathrm{m}^{2}\right)\end{array}$} \\
\hline & Min. & Max. & Std. Dev. & Min. & Max. & Std. Dev. & Min. & Max. & Std. Dev. \\
\hline Esmeraldas & 5 & 46 & 9.57 & 6 & 80 & 13.30 & 8.8 & 9.7 & 0.67 \\
\hline Manta & 5 & 39 & 7.55 & 10 & 96 & 20.93 & 6.7 & 10.5 & 0.68 \\
\hline Puerto López & 5 & 31 & 7.22 & 8 & 74 & 13.07 & 1.1 & 8.6 & 0.46 \\
\hline La Libertad & 5 & 47 & 6.72 & 4 & 93 & 21.29 & 6.3 & 10.5 & 0.69 \\
\hline Salinas & 5 & 35 & 6.67 & 8 & 58 & 16.98 & 3.4 & 8.4 & 0.52 \\
\hline TAO buoy $2 n$ & 5 & 67 & 10.50 & 21 & 92 & 15.15 & 6.9 & 11.3 & 0.71 \\
\hline TAO buoy 0n & 6 & 88 & 10.68 & 3 & 95 & 20.84 & 5.9 & 11.3 & 0.93 \\
\hline TAO buoy $2 s$ & 6 & 92 & 13.43 & 2 & 98 & 20.15 & 6.2 & 11.3 & 0.89 \\
\hline
\end{tabular}




\section{RESULTS}

Fig. 12 shows the spatial eigenvectors, $F_{j}\left(\mathrm{x}_{m}\right)$, of the first three modes, $j=1,2,3$, and their corresponding amplitude time series, $A_{j}(t)$, resulting from EOF decomposition of the anomaly time series, $X\left(\mathrm{x}_{m}, t\right)$, using only the longest two records of the coastal station data (that obtained at La Libertad and Manta). The spatial function of the first mode EOF, $F_{1}\left(\mathrm{x}_{m}\right)$, accounting for $70.9 \%$ of the variance, shows that most of the variability of the temperature anomaly is centered around $40 \mathrm{~m}$ depth where the average base of the thermocline is found. The amplitude time series, $A_{1}(t)$, show substantial interannual variation, with differences from the climatology up to $10^{\circ} \mathrm{C}$ (occurring in 1997-1998; Fig. 12). The second and third modes, $F_{2}\left(\mathrm{x}_{m}\right)$ and $F_{3}\left(\mathrm{x}_{m}\right)$, account for $9.9 \%$ and $8.1 \%$ of the variance and describe vertical and horizontal (latitudinal) deviations from the basic thermal structure defined by the thermocline (EOF 1). The corresponding amplitude time series, $A_{2}(t)$ and $A_{3}(t)$, show lower amplitude variations and are markedly different from $A_{1}(t)$. The spatial structure in $F_{j}\left(\mathrm{x}_{m}\right)$ of the first three modes shows that most of its variability is contained in the mixed layer (as expected).

Fig. 13 shows results of the EOF decomposition including anomaly data from all of the coastal stations, but limited in temporal extent to the duration of the short records (11 years dating back to 2004). The first three EOF modes, $F_{j}\left(\mathrm{x}_{m}\right)$ for $j=1,2,3$, and their corresponding amplitude time series, $A_{j}(t)$, account for $44.2 \%, 13.4 \%$, and $8.1 \%$ of the variance, respectively. The spatial structure of the first EOF mode, $F_{1}\left(\mathrm{x}_{m}\right)$, from these data is quite similar to that when using only the 2 stations with the longest records 
(Fig. 12). The general nature of the $2^{\text {nd }}$ and $3^{\text {rd }}$ mode EOFs, $F_{2}\left(x_{m}\right)$ and $F_{3}\left(x_{m}\right)$, is not as similar in spatial structure, and contains qualitatively more latitudinal variation. A comparison of the amplitude time series, $A_{j}(t)$, of modes $j=1,2,3$, between the long and short record EOF decompositions is shown in Fig. 14. Also shown are lagged cross-correlations between each $A_{j}(t)$ from the long record decomposition and each of the other three $A_{j}(t)$ from the decomposition of the short records. Significant levels are based on the Bootstrap method of Ebisuzaki (1997) using 10000 time series with the same amplitude power spectra but with random phases as the input time series.

Results indicate that the first and third mode EOF amplitude time series, $A_{1}(t)$ and $A_{3}(t)$, from each decomposition are significantly correlated $(\mathrm{R}=0.95$ and $\mathrm{R}=0.60$, respectively; each occurring at zero lag), whereas correlations between $A_{2}(t)$ of each decomposition are not significant. The uncorrelated $A_{2}(t)$ could be a result of smaller length scale variability, aliasing of higher frequency variability creeping into the time series, or orthogonality constraints in the EOF decomposition of the data.

The strong correlation between the dominant first mode EOF amplitude time series, $A_{1}(t)$, of the long and short record decomposition shows that the longer record $A_{1}(t)$ - resulting from decomposition of only 2 coastal stations - behaves similarly to the short record $A_{1}(t)$ that results from decomposition of all 5 coastal stations. Considering that the dominant spatial EOF's, $F_{1}\left(\mathrm{x}_{m}\right)$, from each decomposition are similar, also suggests that the first mode amplitude time series, $A_{1}(t)$, of the long record decomposition should contain the bulk variability of the thermocline representative of the coastal stations as a whole. On the other hand, even though the $3^{\text {rd }}$ mode from 
each short and long record decomposition has similar spatial structure, $F_{3}\left(\mathrm{x}_{m}\right)$, and the corresponding $A_{3}(t)$ are correlated, the $2^{\text {nd }}$ mode $F_{2}\left(\mathrm{x}_{m}\right)$ are not as similar and the $A_{2}(t)$ are not correlated, making it difficult to assign physical interpretation other than general characteristics (e.g., latitudinal or vertical structure). For completeness, we will retain the $2^{\text {nd }}$ and $3^{\text {rd }}$ modes in further comparison with other data, but physical interpretation will be necessarily limited.

The variability of the upper water column observed by the coastal stations is compared with temperature profiles obtained from TAO buoys just to the west of the Galápagos, outside the geographic boundaries of the Ecuadorian Sea, and open to unimpeded influence from the central Pacific. As with the coastal station records, we subtract the climatology from the filtered TAO buoy data and decompose these anomaly time series into orthogonal EOF modes (using Eq. 2 and 3). Fig. 15 shows the first three spatial EOF modes, $F_{j}\left(\mathrm{x}_{m}\right)$ for $j=1,2,3$, and their corresponding amplitude time series, $A_{j}(t)$. These modes are directly comparable to that obtained for the long record coastal station data (Fig. 12). The first spatial EOF mode, $F_{1}\left(\mathrm{x}_{m}\right)$, of the TAO buoys, accounting for $71.1 \%$ of the variance, represents deviations in temperature from the climatological mean thermocline, and varies nearly uniformly horizontally across the equator. This behavior is very similar to $F_{1}\left(\mathrm{x}_{m}\right)$ from the coastal station data (Fig. 12), although the maximum variation in $F_{1}\left(\mathrm{x}_{m}\right)$ is about $10 \mathrm{~m}$ deeper at the TAO stations. The corresponding amplitude time series for the first mode, $A_{1}(t)$, from TAO data also shows very similar temporal variability and magnitude as the coastal station data, with maximum deviation from the climatological mean of $11^{\circ} \mathrm{C}$ 
occurring during the 1997-1998 time period. The second and third EOF's, $F_{2}\left(\mathrm{x}_{m}\right)$ and $F_{3}\left(x_{m}\right)$, contain variability (10 and $9 \%$, respectively) latitudinally about the equator and vertically relative to the first spatial mode $F_{1}\left(\mathrm{x}_{m}\right)$. The amplitude time series from the $2^{\text {nd }}$ and $3^{\text {rd }}$ modes, $A_{2}(t)$ and $A_{3}(t)$, show limited distinguishable energetic events. The nature of the $2^{\text {nd }}$ and $3^{\text {rd }}$ EOF spatial modes, $F_{2}\left(\mathrm{x}_{m}\right)$ and $F_{3}\left(\mathrm{x}_{m}\right)$, are slightly different in character than those same modes from the coastal station data. This higher mode variability is not easily explained owing to the orthogonality constraints in the EOF decomposition and uncertainties in the possible (but unknown) aliasing of the coastal station data (particularly the $2^{\text {nd }}$ mode). Higher modes $(j>3)$ in all data sets each independently represent no more than $3 \%$ of the variance and are not considered further.

A comparison of the EOF amplitude time series, $A_{j}(t)$, from the decomposition of the anomaly data from the coastal station long records (close to shore) and the TAO buoys (west of the Galápagos) are shown in Fig. 16. Qualitatively, the time series from the first EOF mode, $A_{1}(t)$, are very similar, whereas the $2^{\text {nd }}$ and $3^{\text {rd }}$ modes, $A_{2}(t)$ and $A_{3}(t)$, do not show any obvious relationship. Lagged cross-correlations between the corresponding modes from the two locations are also shown in Fig. 16. Table 3 summarizes the maximum correlation and significance level (from Ebisuzaki 1997) for the combinations of cross-correlations from the various EOF modes between coastal and TAO stations. The first mode, $A_{1}(t)$, between the coastal stations and TAO buoy locations are significantly correlated with maximum correlation $(R=0.86)$ occurring at zero lag; however, the $2^{\text {nd }}$ and $3^{\text {rd }}$ EOF modes, $A_{2}(t)$ and $A_{3}(t)$, are not significantly 
correlated ( $R$ ranging $0.16-0.28$ ). This suggests that the bulk (about $74 \%$ ) of the variance in $A_{1}(t)$ of the temperature profile anomaly observed in the long record coastal stations is explained by similar observations west of the Galápagos. 
Table 3. Cross-correlations between EOF amplitude time series from coastal stations and TAO buoys. Significance levels in parenthesis as determined by Ebisuzaki (1997).

\begin{tabular}{|c|c|c|c|c|}
\hline & \multicolumn{3}{|c|}{ TAO } \\
\hline & & EOF 1 & EOF 2 & EOF 3 \\
\hline \multirow{3}{*}{ 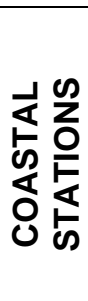 } & EOF 1 & $\begin{array}{c}0.86 \\
(0.28)\end{array}$ & $\begin{array}{c}0.28 \\
(0.28)\end{array}$ & $\begin{array}{c}0.28 \\
(0.22)\end{array}$ \\
\hline & EOF 2 & $\begin{array}{c}0.27 \\
(0.20)\end{array}$ & $\begin{array}{c}0.23 \\
(0.19)\end{array}$ & $\begin{array}{c}0.16 \\
(0.17)\end{array}$ \\
\hline & EOF 3 & $\begin{array}{c}0.28 \\
(0.22)\end{array}$ & $\begin{array}{c}0.25 \\
(0.21)\end{array}$ & $\begin{array}{c}0.17 \\
(0.15)\end{array}$ \\
\hline
\end{tabular}




\section{DISCUSSION}

\subsection{ENSO}

Widely known El Niño Southern Oscillation (ENSO) indices derived in the central Pacific Ocean were compared to the anomaly data from the coastal stations and TAO buoys to determine if the variability in the coastal Ecuadorian Sea is impacted by larger scale processes. ENSO indices are prominently used to quantify strong interannual variability in the central equatorial Pacific, and are commonly defined based on satellite-derived SST anomalies in the $3.4 \mathrm{EI}$ Niño region between $5^{\circ} \mathrm{N}-5^{\circ} \mathrm{S}, 170^{\circ} \mathrm{W}$ $-120^{\circ} \mathrm{W}$, and in the $1+2$ region $\left(0^{\circ}-10^{\circ} \mathrm{S}, 90^{\circ} \mathrm{W}-80^{\circ} \mathrm{W}\right)$, closest to the study area (Fig. 17; Rasmusson and Carpenter 1982; Huang et al. 2015). Fig. 18 shows the time series of Niño 3.4 and Niño 1+2 regions, spanning the duration of the study (19922014). Both ENSO time series were compared to the EOF amplitude time series, $A_{j}(t)$ (Eq. 3), of the anomaly data at both the coastal stations and the TAO buoys (shown later in Fig. 20 and Fig. 21). El Niño (warm) episodes are determined in various ways, and herein defined as five consecutive 3-month running mean SST anomalies that exceed a $0.5^{\circ} \mathrm{C}$ threshold in the Niño 3.4 region (following Kousky and Higgins 2007). Also indicated on Fig. 18 are the defined El Niño episodes (gray areas above $+0.5^{\circ} \mathrm{C}$ anomalies) and the cold periods (gray areas below $-0.5^{\circ} \mathrm{C}$ anomalies) referred to as La Niña episodes (also after Kousky and Higgins 2007). Although no more common than El Niño or La Niña periods, unmarked (no shading) periods are considered "normal" conditions.

We have indicated in Fig. 7 and Fig. 11 the corresponding El Niño (black squares in the top of the plot) and La Niña periods (gray squares in the top of the plot). In 
general, all coastal stations and TAO buoys show higher heat content and a deepening of the $20^{\circ} \mathrm{C}$ isotherm, while during "normal" and La Niña periods, the $20^{\circ} \mathrm{C}$ isotherm is found closer to the surface, and heat content in the upper water column (above $100 \mathrm{~m}$ ) at the coastal stations is less than that observed at the TAO buoys to the west of the Gálapagos Islands. Fig. 19 shows the mean and standard deviation of the HC, MLD, depth of the $20^{\circ} \mathrm{C}$ isotherm, and the first mode amplitude time series, $A_{1}(t)$, all from both coastal station and TAO data for El Niño, normal, and La Niña periods. These mean statistics show that the water is warmer during El Niño periods (higher $\mathrm{HC}$, deeper $20^{\circ} \mathrm{C}$ isotherm, and increased $A_{1}(t)$ ), and coldest during La Niña (lower HC, shallower $20^{\circ} \mathrm{C}$ isotherm, and decreased $\left.A_{1}(t)\right)$ both at the coastal stations and the TAO buoys. These results are perhaps not unexpected due to established links between ENSO events and coastal upwelling along the coast of Perú [Alheit and Niquen, 2004; Chavez et al., 2008] and Galápagos [Eden and Timmermann, 2004; Karnauskas et al., 2007]. Observations at the TAO buoys show slightly higher upper water column temperatures and heat content than the coastal data during all periods. MLD depths increase (decrease) during El Niño's (La Niña's) at the TAO buoys, but not at the coastal stations, perhaps due to structure in the temperature profile in the upper water column that may be due to past local events (fossil thermoclines) or higher coastal variability.

Fig. 20 shows a comparison between the first EOF amplitude time series, $A_{1}(t)$, from the coastal station temperature anomaly data (at $81^{\circ} \mathrm{W}$ longitude; Table 1 ) and ENSO 3.4 and $1+2$ indices. Qualitatively the records follow a similar oscillation, with larger ENSO values corresponding to El Niño events, particularly during the 1997-98 
event. Also, shown in Fig. 20 are lagged cross-correlations between $A_{1}(t)$ and each ENSO index, with $A_{1}(t)$ significantly correlated to the ENSO index in the central Pacific (Niño 3.4; $R=0.65$ ) and eastern equatorial Pacific (Niño 1+2; $R=0.74$ ) regions. Significance levels were again determined from the Bootstrap method of Ebisuzaki (1997) and summarized in

Table 4. Higher mode EOF amplitude time series, $A_{2}(t)$ and $A_{3}(t)$, are not significantly correlated to the ENSO indexes (Fig. 20;

Table 4). Comparisons between $A_{j}(t)$ for modes $j=1,2,3$ of the temperature anomalies observed at the TAO buoys (along $95^{\circ} \mathrm{W}$ longitude) and 3.4 and 1+2 ENSO indices (Fig. 21) show similar relationships, with significant correlation with the central Pacific (Niño 3.4; $R=0.71$ ) and eastern equatorial Pacific (Niño $1+2 ; R=0.86$ ) that is slightly higher than at the coastal stations. Similarly to the coastal station data, correlations between higher EOF mode amplitude time series, $A_{2}(t)$ and $A_{3}(t)$, are not significant (

Table 4).

EOF mode 1 variability, $A_{1}(t)$, for anomaly time series temperature data from both coastal stations and TAO buoys are strongly coupled to each other, and to interannual ENSO variations. On the other hand, higher mode EOF amplitude time series, $A_{2}(t)$ and $A_{3}(t)$, are not coupled to each other or ENSO variability. These higher modes have lower amplitude and smaller time scale variability, and may be due to local ocean processes unrelated to larger scale ocean variability such as coastal winds, simply constrained by the orthogonality constraints in the EOF decomposition of the data, or in the case of the coastal stations may be susceptible to aliasing from short duration storm events. 
Table 4. Cross-correlations between the coastal stations (CS) and TAO buoys with ENSO SST 3.4 and $1+2$ region indices. 95\% significance levels are given in parenthesis (determined by Ebisuzaki (1997). Numbers in bold are significant).

\begin{tabular}{|c|c|c|c|}
\hline \multirow{2}{*}{\multicolumn{2}{|c|}{ EOF }} & El Niño 3.4 & El Niño $1+2$ \\
\hline & & $\mathrm{R} \max$ & $\mathrm{R} \max$ \\
\hline \multirow{2}{*}{ Mode 1} & CS & $\begin{array}{c}\mathbf{0 . 6 5} \\
(0.32)\end{array}$ & $\begin{array}{c}\mathbf{0 . 7 4} \\
(0.32) \\
\end{array}$ \\
\hline & TAO & $\begin{array}{c}\mathbf{0 . 7 1} \\
(0.28)\end{array}$ & $\begin{array}{c}\mathbf{0 . 8 6} \\
(0.28)\end{array}$ \\
\hline \multirow{2}{*}{ Mode 2} & CS & $\begin{array}{c}0.30 \\
(0.22)\end{array}$ & $\begin{array}{c}0.29 \\
(0.22)\end{array}$ \\
\hline & TAO & $\begin{array}{c}0.32 \\
(0.23)\end{array}$ & $\begin{array}{c}0.34 \\
(0.23)\end{array}$ \\
\hline \multirow{2}{*}{ Mode 3} & CS & $\begin{array}{c}0.24 \\
(0.22)\end{array}$ & $\begin{array}{c}0.21 \\
(0.22)\end{array}$ \\
\hline & TAO & $\begin{array}{c}0.28 \\
(0.19)\end{array}$ & $\begin{array}{c}0.34 \\
(0.19)\end{array}$ \\
\hline
\end{tabular}

Approaches for further analysis of amplitude time series, $A_{j}(t)$, from EOF decomposition of various ocean temperature data has been suggested by several studies, including subtracting the signal defined by the first EOF, $X_{1}\left(x_{m}, t\right)=$ $A_{1}(t) F_{1}\left(\mathrm{x}_{m}\right)$, from the data, $X\left(\mathrm{x}_{m}, t\right)$, and then recomputing EOF's on the residual (as suggested by Enfield and Mestas-Nuñez 2000; Cane et al. 1997). Another method useful for discerning propagating signals (or modes) in the time series array [Wallace and Dickinson, 1972; Rasmusson et al., 1981] involves computing the Hilbert transform, $H()$, of the data such that $Y\left(\mathrm{x}_{m}, t\right)=H\left(X\left(\mathrm{x}_{m}, t\right)\right)$, and constructing a complex time series where $Z\left(\mathrm{x}_{m}, t\right)=X\left(\mathrm{x}_{m}, t\right)+i Y\left(\mathrm{x}_{m}, t\right)$ that is subjected to a complex EOF analysis (following Enfield and Mestas-Nuñez 2000). Each of these 
methods were explored with corresponding amplitude time series of spatial modes compared with ENSO indices; however, no easily deduced insight was obtained. The ENSO signal was present, but is no more illuminating in terms of describing the variability than the present analysis, and in some cases (e.g., the complex decomposition), the interpretation was more difficult.

\subsection{Winds}

Warm episodes in the Eastern Pacific have been observed and documented since the last century [Rasmusson and Carpenter, 1982], however it was not until 1966, when Bjerkness clearly linked the interannual fluctuations in SST with changes in the zonal wind component near the equator. In order to determine the relationship between wind velocity and the interannual variability of Sea Temperature in the coastal stations, temperature profile observations are compared with daily averaged zonal and meridional winds $(\mathrm{U}$ and $\mathrm{V}$ components, respectively, in the usual oceanographic convention) with $0.75^{\circ}$ horizontal resolution derived using more than 50 types of sensor by the European Centre for Medium-Range Weather Forecasts (ECMWF) Global ERAInterim reanalysis [Berrisford et al., 2009]. This reanalysis is based on a global atmospheric reanalysis from 1979, continuously updated in real time [Dee et al., 2011].

To best compare interannual variations in ECWMF winds with coastal station data, climatological wind variations were computed and subtracted from the wind time series to produce anomaly wind fields similar to the analysis of the coastal station and TAO buoy temperature profile analysis. Wind anomalies were then averaged 
backwards in time over $1-29$ days prior to the actual date when the CTD casts were made. This averaging window was applied to every previous time step in the daily wind time series. The temporally averaged zonal and meridional wind time series, $U\left(\mathrm{v}_{n}, t, \tau\right)$ and $V\left(\mathrm{v}_{n}, t, \tau\right)$, respectively, at the $\mathrm{n}$ spatial grid locations, $\mathrm{v}_{n}$, spanning the eastern equatorial Pacific between $10^{\circ}$ north and south of the equator and from $96^{\circ} \mathrm{W}$ and the coastline, are compared with the first mode EOF amplitude time series, $A_{1}(t)$, from the long record coastal station data by computing lagged cross-correlations for values of $\tau=1-29$ days. Correlations generally increased as lag, $\tau$, increased, with maximum values occurring at 29 day averages.

Fig. 22 shows the spatial variation in the maximum correlation (for $\tau=29$ days) between $A_{1}(t)$ and both $U\left(\mathrm{v}_{n}, t, \tau\right)$ and $V\left(\mathrm{v}_{n}, t, \tau\right)$. Lags at which the maximum correlation was significant (greater than 0.27 based on Ebisuzaki 1997) was between 0 and 5 days, indistinguishable from the monthly sampled coastal profile sampling interval. The spatial pattern of the wind correlations to the coastal station data show strong negative correlation $(R=-0.66)$ in the Colombian Basin to the north of the coastal stations in both the zonal and meridional winds, suggesting that south-west winds are correlated to warmer waters (positive temperature anomalies) in the coastal stations.

Similarly, strong correlations were observed to the north and just offshore the Perú coastline, but with negative correlation to $U\left(\mathrm{v}_{n}, t, \tau\right)(\mathrm{R}=-0.5)$ and positive correlation to $V\left(\mathrm{v}_{n}, t, \tau\right)(\mathrm{R}=0.5)$. In each of these areas, the nature of the correlations suggests that stronger than normal equatorward winds (blowing toward the SW in the 
Colombian Basin, and toward the NW off the coast of Perú) results in warmer coastal surface waters (i.e., higher values of $A_{1}(t)$ ). These winds are favorable for upwelling at latitudes a few degrees north and south of the equator, but not right at the equator where Coriolis goes to zero. Despite upwelling favorable winds to the north and south of the equator, the coastal station temperature anomalies show warmer surface waters, consistent with a convergence of surface wind driven currents and a pilling-up at the equator of warmer Colombian and Peruvian surface waters near the coast. Oppositely, colder waters at the coastal stations, associated with La Niña events are coupled to poleward directed northeastern and southeastern winds (blowing away from the equator) in the Colombian basin and off the coast of Perú [Kessler, 2006]. This indicates that wind field variations similar to these close to the coast north and south of the equator results in convergences and divergences of surface waters at the equator, leading to warmer surface waters during stronger equatorward winds and colder surface waters during poleward winds.

The correlation between the winds and $A_{1}(t)$ generally decreased with longitudinal distance away from the coastal station, except for a region to the south west of the Galápagos where meridional winds were significantly correlated $(R=$ +0.62 ), indicating that anomalously northerly winds (equator-wards) are coupled to warmer waters in the Ecuadorian Sea. This correlation may arise due to the wind fields themselves being driven by the same larger scale process that is driving the coastal ocean mixed layer dynamics. 
We can evaluate the nature of the wind variations in the Colombian basin and to the south of the Galápagos by selecting specific regions with high correlation to $A_{1}(t)$, and decomposing the wind fields into EOF's as we did with the coastal and TAO buoy data (Eq. 2-3). Fig. 23 shows the first spatial mode EOF's, $F_{1}\left(x_{m}\right)$, and their corresponding amplitude time series, $A_{1}(t)$, from decomposition of the anomaly zonal, $U\left(\mathrm{v}_{n}, t, \tau\right)$, and meridional, $V\left(\mathrm{v}_{n}, t, \tau\right)$, winds for the regions outlined in Fig. 22 . The variance explained by the first EOF mode ranges $87-91 \%$, and thus higher modes are not considered. The amplitude time series, $A_{1}(t)$, are compared with the Niño 3.4 and 1+2 ENSO indices in Fig. 24. Also, shown are the lagged cross-correlations that indicate significant coupling between wind variations and ENSO indices at 0 lags (except for the area to the southwest of the Galápagos where zonal wind seems to be lagged by a month). Not surprisingly, correlations are higher for the ENSO indices closest to the wind region. This analysis suggests that interannual wind variations in the eastern equatorial Pacific are largely coupled to ENSO variations, and are consistent with a convergence of surface waters near the coast that links the interannual wind variations to the fluctuations in upper ocean temperature of the coastal Ecuadorian Sea. In the Galápagos area, where the upwelling is modulated from the EUC, Northerly winds (positive V) appear to be coupled to the warming of the coastal areas. Positive correlations to the south of the Galápagos are likely the result of wind forcing in that region being driven by the same large scale process that is driving the coastal variability (but with opposite interannual variations in wind strength and direction). 


\subsection{Potential sources of uncertainty in the analyses}

Observations obtained at the coastal stations occurred on an approximately monthly interval over the course of the data set, with a few periods where no data were collected, the instruments malfunctioned, or the data were deemed unusable. These time series appear qualitatively to well capture the seasonal (climatological) variability; that is, well known seasonal variations in temperature in the upper water column are clearly present. However, the sampling interval is too large to represent variability at daily or weekly time scales which can be large during storm events, presenting the possibility for aliasing in the time series. At the TAO buoys, the data are sampled continuously from fixed sensors at particular depths, and monthly time series determined from averaging. Thus, for TAO data the daily and weekly variability are averaged out and the possibility of aliasing is generally eliminated from the TAO time series. The climatological data from both the coastal stations and TAO buoys are subtracted from the time series profile and a subsequent EOF decomposition of the anomaly data is performed. Considering that the first EOF mode amplitude time series from the coastal stations is so strongly coupled to the TAO buoy first mode EOF amplitude time series suggests that the interannual variability of the temperature profiles at coastal stations is well captured, and that aliasing is not likely a problem. On the other hand, the lack of correlation between TAO and coastal station data at higher EOF modes presents the possibility that aliasing has influenced the smaller time scale (perhaps shorter wavelength) temperature variability.

The lag of maximum correlation between the TAO buoys and the coastal station's first EOF mode amplitude time series occurs at zero, indicating a synchronous (at 
monthly time scales) oscillation of the bulk of the thermal variability associated with ENSO signals. Kessler et al. (1995) suggest that Kelvin waves are observed to be forced west of the date line and propagated eastward at a speed of $2.4 \mathrm{~m} / \mathrm{s}$, travelling at approximately $1.9^{\circ}$ per day (Iongitudinally). At this speed the lags at monthly sampling are indistinguishable over the distance between the outer (TAO buoy, $95^{\circ} \mathrm{W}$ ) and inner (Coastal Station, $81.5^{\circ} \mathrm{W}$ ) parts of the study area.

As an aside, along with the CTD casts performed monthly at the coastal stations, water samples for chemical properties were taken as reported by Carrillo (2012; 2013). Carrillo suggests that strong El Niño (warm) events produce more oxygenated water columns (see Figure 2 in Carrillo 2013), while relatively colder periods (La Niña events) before (e.g., 1995/1996) and after (e.g., 1999/2000) warm events produce minimum observed oxygen concentrations throughout the water column. Large changes in oxygen could have potential consequences on the marine ecosystem in general. As indicated in FAO records, a decrease in dissolved oxygen is recorded during 1982/1983, 1990 and 1997/1998, coincident with warmer periods in the equatorial Pacific. Further analysis linking the effects of seasonal and interannual temperature, salinity and wind variability, would be needed to better understand the ecosystem dynamics and effects on productivity in the Ecuadorian Sea. 


\section{CONCLUSIONS}

Monthly time series of temperature and salinity profiles obtained over 22 years at five latitudinally-separated stations located $8 \mathrm{~nm}$ from the coast in the Ecuadorian Sea were analyzed and compared to data outside of the Galápagos to examine interannual variability in the upper water column of coastal waters. CTD data were obtained at 2 of the 5 stations from 1992-2014 by the Oceanographic Institute of the Navy (INOCAR), and at the 3 other stations from 2004-2014 by the National Fisheries Institute (INP) of Ecuador, and are ongoing today. Coastal station data show strong seasonal variability which is removed by subtracting monthly climatological means from the time series data. These anomaly time series have substantial interannual variability in the $20^{\circ} \mathrm{C}$ isotherm depth, heat content over the upper $100 \mathrm{~m}$ of the water column, and depth of the mixed layer (determined from temperature profiles). Each of these time series suffers from incomplete time series owing to periods when the $20^{\circ} \mathrm{C}$ isotherm or the mixed-layer depth was below $100 \mathrm{~m}$, nor does it include heat content contributions deeper than $100 \mathrm{~m}$. As a consequence, the time series are more difficult to evaluate. To better represent the anomaly time series data, all profiles are decomposed into orthogonal components using standard EOF analysis [Barnett, 1984].

Two analyses were done on the coastal stations, the first included only the 2 longest records (spanning 22 years), the second involved all 5 coastal records, but only spanned the overlapping portions dating back to 2004 (and spanning 11 years). Similar characteristics in the spatial factors were qualitatively observed in the first three EOF modes of each decomposition. Cross-correlations between mode 1 EOF amplitude time series from the short and long record decompositions was very high ( $R$ 
$=0.95)$; however, the correlations of the higher mode EOF amplitude time series were much lower. As a result, the EOF amplitude time series for the longer records are used to quantify the variability in the coastal records.

The first mode EOF contains the bulk of the variability $(70.9 \%)$ in the thermocline depth. The second and third spatial modes describe variations about the equator (latitudinal changes; 9.92\%), and vertical and horizontal variations (8.09\%). Owing to orthogonality constraints in the decomposition of the data, and limitations based on possibilities of aliasing in the raw time series, physical interpretation of higher modes is not easily accomplished. Corresponding amplitude time series show the temporal changes of the EOF factors.

Comparisons of coastal anomaly time series data are made with observations obtained from TAO/Triton buoys located at $95^{\circ} \mathrm{W}$ between $2^{\circ} \mathrm{N}$ and $2^{\circ} \mathrm{S}$, just (850 $\mathrm{nm}$ ) to the west of the Galápagos Islands. Anomaly time series were obtained from the TAO data in a similar manner as for the coastal station data, and subsequently subjected to the same EOF decomposition. The first three spatial EOF modes at the TAO stations (representing $71.1,7.35$, and $6.06 \%$ of the variance) describe variability in the thermocline depth, and latitudinal variations, qualitatively similar to observations from the coastal stations. Cross-correlations show that the first mode EOF amplitude time series from the TAO buoys and coastal stations is very strongly correlated $(R=$ 0.86), showing that the bulk of the temperature profile interannual variability close to shore (within $8 \mathrm{~nm}$ ) is strongly coupled to variability to the west of the Galápagos 
Islands outside of the topographically delineated Ecuadorian Sea. Higher mode EOF amplitude time series are not significantly correlated.

The first mode EOF amplitude time series at the coastal stations and TAO buoys were also compared with ENSO indices derived from satellite SST observations. Results show that first mode EOF's from both the coastal stations and TAO buoys were significantly correlated to the ENSO signal of SST anomaly at regions 3.4 and $1+2$. The second and third EOF modes (collectively representing about $20 \%$ of the interannual variance) are not significantly correlated to the ENSO signals.

The first EOF mode of the coastal stations was compared to wind data averaged over the previous 29 days from ECMWF ERA-Interim Global reanalysis. Highest correlations were found close to the coast, north and south of the coastal stations, in the Colombian Basin, off the coast of Peru to the south, and southwest of the Galápagos. Cross-correlation of the orthogonal wind components of the wind in these two areas show significant coupling with ENSO $1+2$ and 3.4 regions closest to each area. These results are consistent with a convergence of surface waters near the coast that links the interannual wind variations to the fluctuations in upper ocean temperature of the coastal Ecuadorian Sea.

Future work needs to focus on extending the spatial variability of the study area from the coast towards the Galápagos Islands, for which several sources of data have been identified and developed in the Eastern-Pacific countries from international agreements, such as the South Pacific Permanent Commission (CPPS). a) Seasonal cruises, once a year in the Ecuadorian Sea (as well as north and south of the country, 
coordinated by the CPPS) since the early 1980's would provide better spatial information of the water column down to $500 \mathrm{~m}$ of depth from the South American coast to west of the Galápagos Islands. b) Better understanding of the influence of the Colombia Basin and Humboldt current on interannual variability of the Ecuadorian Coastal stations could be achieved by including buoy data from Peru's National Hydrography Direction of the Navy (DHN), as well as coastal stations from the Colombian Oceanographic and Hydrographic Research center of the Pacific (CPPS Dimar). 


\section{REFERENCES}

Alheit, J., and M. Niquen (2004), Regime shifts in the Humboldt Current ecosystem, Prog. Oceanogr., 60(2-4), 201-222, doi:10.1016/j.pocean.2004.02.006.

Ballón, M., C. Wosnitza-Mendo, R. Guevara-Carrasco, and A. Bertrand (2008), The impact of overfishing and El Niño on the condition factor and reproductive success of Peruvian hake, Merluccius gayi peruanus, Prog. Oceanogr., 79(2-4), 300-307, doi:10.1016/j.pocean.2008.10.016.

Barnett, T. P. (1984), Interaction of the Monsoon and Pacific Trade Wind System at Interannual Time Scales. Part III: A Partial Anatomy of the Southern Oscillation, Mon. Weather Rev., 112(12), 2388-2400, doi:10.1175/15200493(1984)112<2388:IOTMAP>2.0.CO;2.

Berrisford, P., D. Dee, K. Fielding, M. Fuentes, P. Kallberg, S. Kobayashi, and S. Uppala (2009), The ERA-Interim Archive, ERA Rep. Ser., 1(1), 1-16.

Bertrand, S., B. Dewitte, J. Tam, E. Díaz, and A. Bertrand (2008), Impacts of Kelvin wave forcing in the Peru Humboldt Current system: Scenarios of spatial reorganizations from physics to fishers, Prog. Oceanogr., 79(2-4), 278-289, doi:10.1016/j.pocean.2008.10.017.

de Boyer Montégut, C., G. Madec, A. S. Fischer, A. Lazar, and D. ludicone (2004), Mixed layer depth over the global ocean: An examination of profile data and a profile-based climatology, J. Geophys. Res. C Ocean., 109(12), 1-20, doi:10.1029/2004JC002378.

Cane, M., A. Clement, a Kaplan, Y. Kushnir, D. Pozdnyakov, R. Seager, S. Zebiak, and R. Murtugudde (1997), Twentieth-Century Sea Surface Temperature Trends, Science, 275(5302), 957-60, doi:10.1126/science.275.5302.957.

Carrillo, P. (2012), Comportamiento Del Oxigeno Disuelto En Dos Estaciones Costeras La Libertad Y Manta , Como Aporte Al Conocimiento Del Fenómeno " El Niño ," Acta Ocean. del Pacífico, 17.

Carrillo, P. (2013), Comportamiento del oxígeno disuelto en la columna de agua de las estaciones fijas ecuatorianas 1988-2013, Acta Ocean. del Pacífico, 18(1), 41-48.

Chavez, F. P., P. G. Strutton, G. E. Friederich, R. A. Feely, G. C. Feldman, D. G. Foley, and M. J. McPhaden (1999), Biological and chemical response of the equatorial pacific ocean to the 1997-98 El Nino, Science (80-. )., 286(5447), 2126-2131, doi:10.1126/science.286.5447.2126.

Chavez, F. P., A. Bertrand, R. Guevara-Carrasco, P. Soler, and J. Csirke (2008), The northern Humboldt Current System: Brief history, present status and a view towards the future, Prog. Oceanogr., 79(2-4), 95-105, doi:10.1016/j.pocean.2008.10.012.

Chepurin, G. A., and J. A. Carton (1999), Comparison of retrospective analyses of the global ocean heat content, Dyn. Atmos. Ocean., 29(2-4), 119-145, doi:10.1016/S03770265(99)00004-4.

Cornejo-Rodríguez, M. del P. (1987), Ondas Ecuatoriales atrapadas: Ondas mezcladas de Rossby - gravedad, Acta Ocean. del Pacífico, 4(1), 204-210.

Cornejo-Rodríguez, M. del P., and D. B. Enfield (1987), Propagation and Forcing of HighFrequency Sea Level Variability Along the West Coast of South America, J. Geophys. 
Res., 92(C13), 14323-14334.

Cucalón, E. (1983), Temperature , Salinity and Water Mass Distribution Off Ecuador During an El Niño Event in 1976, Rev. Ciencias del Mar y Limnol., 2(1), 1-25.

Dee, D. P. et al. (2011), The ERA-Interim reanalysis: Configuration and performance of the data assimilation system, Q. J. R. Meteorol. Soc., 137(656), 553-597, doi:10.1002/qj.828.

Deng, W., G. Wei, L. Xie, T. Ke, Z. Wang, T. Zeng, and Y. Liu (2013), Variations in the Pacific Decadal Oscillation since 1853 in a coral record from the northern South China Sea, J. Geophys. Res. Ocean., 118(5), 2358-2366, doi:10.1002/jgrc.20180.

Dijkstra, H. A. (2008), Dynamical Oceanography.

Ebisuzaki, W. (1997), A method to estimate the statistical significance of a correlation when the data are serially correlated, J. Clim., 10(9), 2147-2153, doi:10.1175/15200442(1997)010<2147:AMTETS>2.0.CO;2.

Eden, C., and A. Timmermann (2004), The influence of the Galápagos Islands on tropical temperatures, currents and the generation of tropical instability waves, Geophys. Res. Lett., 31(15), doi:10.1029/2004GL020060.

Enfield, D. B., and a M. Mestas-Nuñez (2000), Global Modes of ENSO and non-ENSO Sea Surface Temperature Variability and Their Associations with Climate, El Niño South. Oscil. Multiscale Var. Glob. Reg. Impacts., 89-112.

Enfield, D. B., M. del P. Cornejo-Rodríguez, R. L. Smith, and P. A. Newberger (1987), The Equatorial Source of propagating variability along the Peru Coast during the 1982-1983 El Niño, J. Geophys. Res., 92(C13), 14335-14346.

Fiedler, P. C., and L. D. Talley (2006), Hydrography of the eastern tropical Pacific: A review, Prog. Oceanogr., 69(2-4), 143-180, doi:10.1016/j.pocean.2006.03.008.

Glynn, P. W., J. L. Maté, A. C. Baker, and M. O. Calderón (2001), Coral Bleaching and Mortality in Panama and Ecuador During the 1997 - 1998 El Niño - Southern Oscillation Event: Spatial / Temporal Patterns and Comparisons With the $1982-1983$ Event, Bull. Mar. Sci., 69(1), 79-109.

Huang, B., V. F. Banzon, E. Freeman, J. Lawrimore, W. Liu, T. C. Peterson, T. M. Smith, P. W. Thorne, S. D. Woodruff, and H. M. Zhang (2015), Extended reconstructed sea surface temperature version 4 (ERSST.v4). Part I: Upgrades and intercomparisons, J. Clim., 28(3), 911-930, doi:10.1175/JCLI-D-14-00006.1.

Huffman, G. J., D. T. Bolvin, E. J. Nelkin, D. B. Wolff, R. F. Adler, G. Gu, Y. Hong, K. P. Bowman, and E. F. Stocker (2007), The TRMM Multisatellite Precipitation Analysis (TMPA): Quasi-Global, Multiyear, Combined-Sensor Precipitation Estimates at Fine Scales, J. Hydrometeorol., 8(1), 38-55, doi:10.1175/JHM560.1.

Jeronimo, G., and J. Gomez-Valdes (2010), Mixed layer depth variability in the tropical boundary of the California Current, 1997-2007, J. Geophys. Res. Ocean., 115(5), doi:10.1029/2009JC005457.

Karnauskas, K. B., R. Murtugudde, and A. J. Busalacchi (2007), The Effect of the Galápagos Islands on the Equatorial Pacific Cold Tongue, J. Phys. Oceanogr., 37(5), 1266-1281, doi:10.1175/JPO3048.1. 
Kessler, W. S. (2006), The circulation of the eastern tropical Pacific: A review, Prog. Oceanogr., 69(2-4), 181-217, doi:10.1016/j.pocean.2006.03.009.

Kessler, W. S., M. J. McPhaden, and K. M. Weickmann (1995), Forcing of intraseasonal Kelvin waves in the equatorial Pacific, J. Geophys. Res., 100(C6), 10613, doi:10.1029/95JC00382.

Kousky, V. E., and R. W. Higgins (2007), An Alert Classification System for Monitoring and Assessing the ENSO Cycle, Weather Forecast., 22(2), 353-371, doi:10.1175/WAF987.1.

Lavín, M. F., P. C. Fiedler, J. A. Amador, L. T. Ballance, J. Färber-Lorda, and A. M. MestasNuñez (2006), A review of eastern tropical Pacific oceanography: Summary, Prog. Oceanogr., 69(2-4), 391-398, doi:10.1016/j.pocean.2006.03.005.

Lee, T., G. Lagerloef, M. M. Gierach, H. Y. Kao, S. Yueh, and K. Dohan (2012), Aquarius reveals salinity structure of tropical instability waves, Geophys. Res. Lett., 39(12), 1-6, doi:10.1029/2012GL052232.

Levitus, S. et al. (2012), World ocean heat content and thermosteric sea level change (02000m), 1955-2010, Geophys. Res. Lett., 39(10), doi:10.1029/2012GL051106.

Lucero, M., and M. del P. Cornejo-Rodríguez (1990), Evidencia de la Corriente de Cromwell entre $92^{\circ} \mathrm{W}$ y $84^{\circ} \mathrm{W}$, observada en periodos normales y durante El Niño 82-83, Acta Ocean. del Pacífico, 6(1), 17-27.

McPhaden, M. J. (2012), A 21st century shift in the relationship between ENSO SST and warm water volume anomalies, Geophys. Res. Lett., 39(May), 1-5, doi:10.1029/2012GL051826.

Michaud, F. et al. (2015), Quaternary sedimentation and active faulting along the Ecuadorian shelf: preliminary results of the ATACAMES Cruise (2012), Mar. Geophys. Res., 36(1), 81-98, doi:10.1007/s11001-014-9231-y.

Morán-Tejeda, E. et al. (2016), Climate trends and variability in Ecuador (1966-2011), Int. J. Climatol., n/a-n/a, doi:10.1002/joc.4597.

Rasmusson, E. M., and T. H. Carpenter (1982), Variations in tropical sea surface temperature and surface wind fields associated with the Southern Oscillation/EI Niño, Mon. Weather Rev., 110(5), 354-384, doi:10.1175/15200493(1982) $110<0354$ :VITSST >2.0.CO;2.

Rasmusson, E. M., P. a. Arkin, W.-Y. Chen, and J. B. Jalickee (1981), Biennial Variations in Surface Temperature over the United States as Revealed by Singular Decomposition, Mon. Weather Rev., 109(3), 587-598, doi:10.1175/15200493(1981)109<0587:BVISTO>2.0.CO;2.

Thomson, R. E., and I. V. Fine (2003), Estimating mixed layer depth from oceanic profile data, J. Atmos. Ocean. Technol., 20(2), 319-329, doi:10.1175/15200426(2003)020<0319:EMLDFO>2.0.CO;2.

Vargas-Angel, B., F. A. Zapata, H. Hernandez, and J. M. Jimenez (2001), Coral and coral reef responses to the 1997-98 El Niño event on the Pacific coast of Colombia, Bull. Mar. Sci., 69(1), 111-132.

Wade, M., G. Caniaux, and Y. Du Penhoat (2011), Variability of the mixed layer heat budget in the eastern equatorial Atlantic during 2005-2007 as inferred using Argo floats, J. 
Geophys. Res. Ocean., 116(8), 1-17, doi:10.1029/2010JC006683.

Wallace, J. M., and R. E. Dickinson (1972), Empirical Orthogonal Representation of Time Series in the Frequency Doman. Part I: Theoretical Considerations, J. Appl. Meteorol., 11(6), 887-892, doi:10.1175/1520-0450(1972)011<0887:EOROTS>2.0.CO;2.

Wyrtki, K. (1975), El Niño-The Dynamic Response of the Equatorial Pacific Oceanto Atmospheric Forcing, J. Phys. Oceanogr., 5(4), 572-584, doi:10.1175/15200485(1975)005<0572:ENTDRO>2.0.CO;2.

Wyrtki, K. (1981), An estimate of equatorial upwelling in the pacific, J. Phys. Oceanogr., 11, 1205-1214. 


\section{FIGURES}
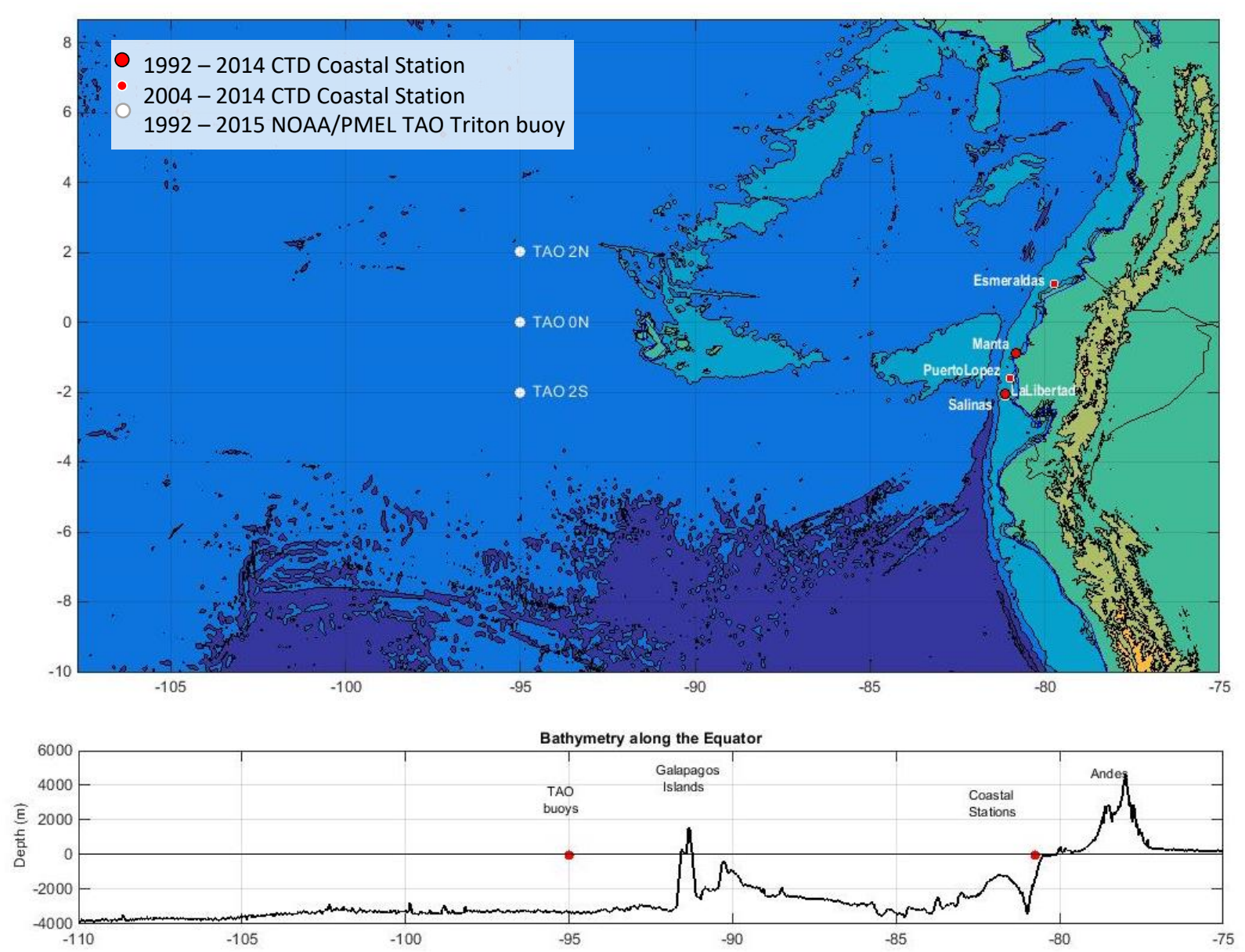

Fig. 1. Upper panel: GEBCO topography/bathymetry of the study area. Coastal stations are shown in red circles, TAO buoys as white circles. Lower Panel: Bathymetric profile along the Equator with TAO buoys and coastal stations in red circles. 

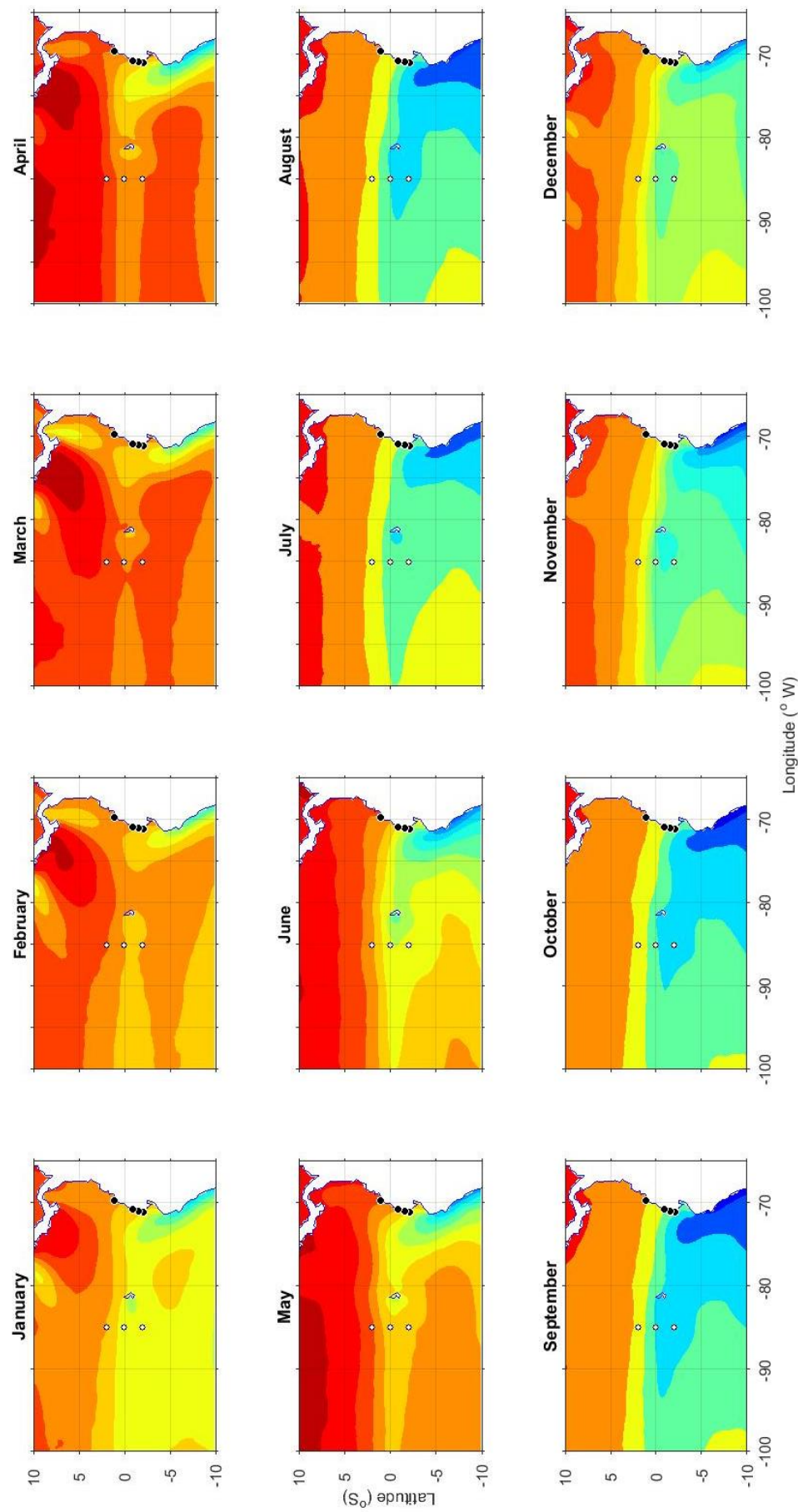

Fig. 2. Sea surface temperature climatology from AVHRR data spanning 1992-2015 from Reynolds, et al., (2009). The locations of coastal stations are shown in dark circles and TAO buoys in white circles. 

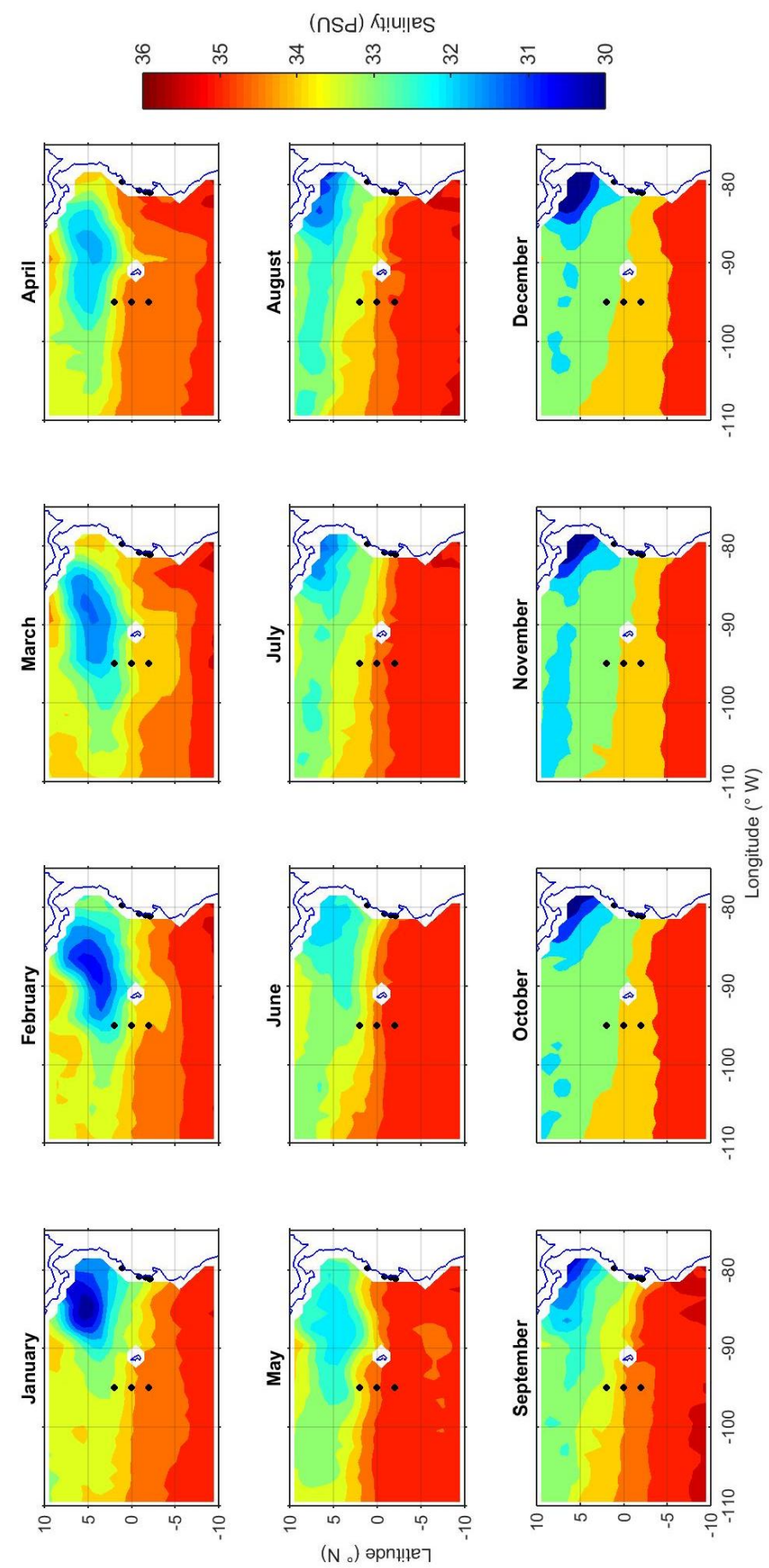

Fig. 3. Surface Salinity Climatology (Aquarius data set from 2011/09 - 2015/05). The locations of coastal stations and TAO buoys are shown in dark circles. 


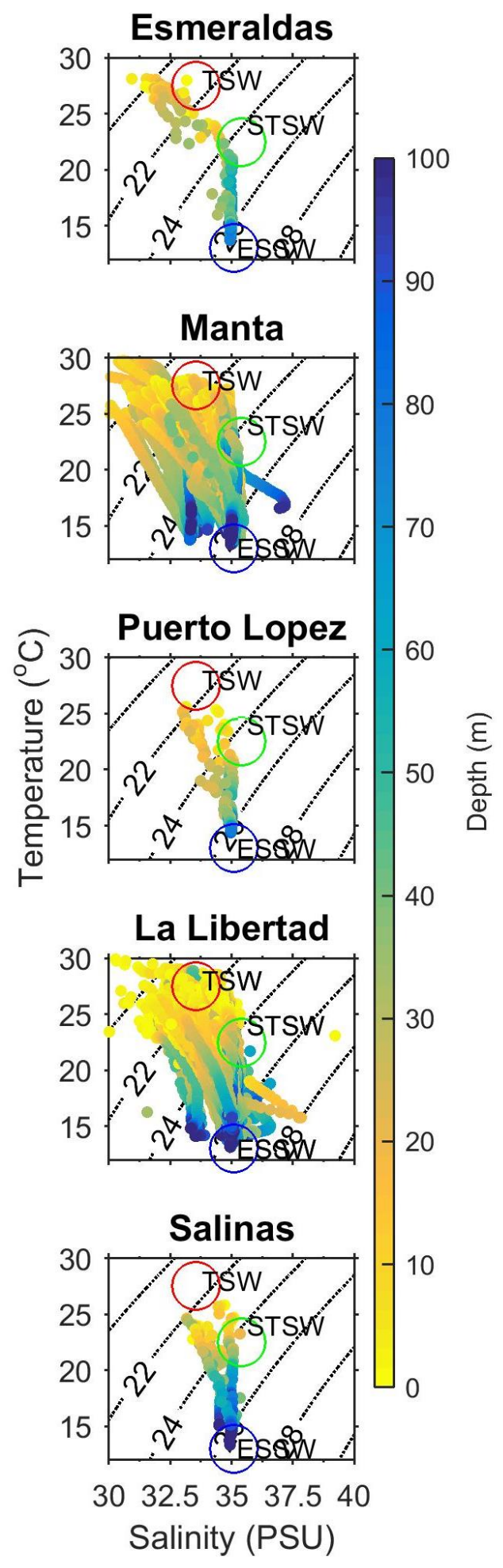

Fig. 4. T/S diagrams for the coastal station data. Panels are ordered by latitude with North upwards. Also shown are T/S signatures for Tropical and Subtropical Surface Waters (from Cucalón 1983). Colors represent depth (scale bar shown on the right). 


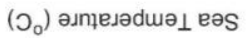

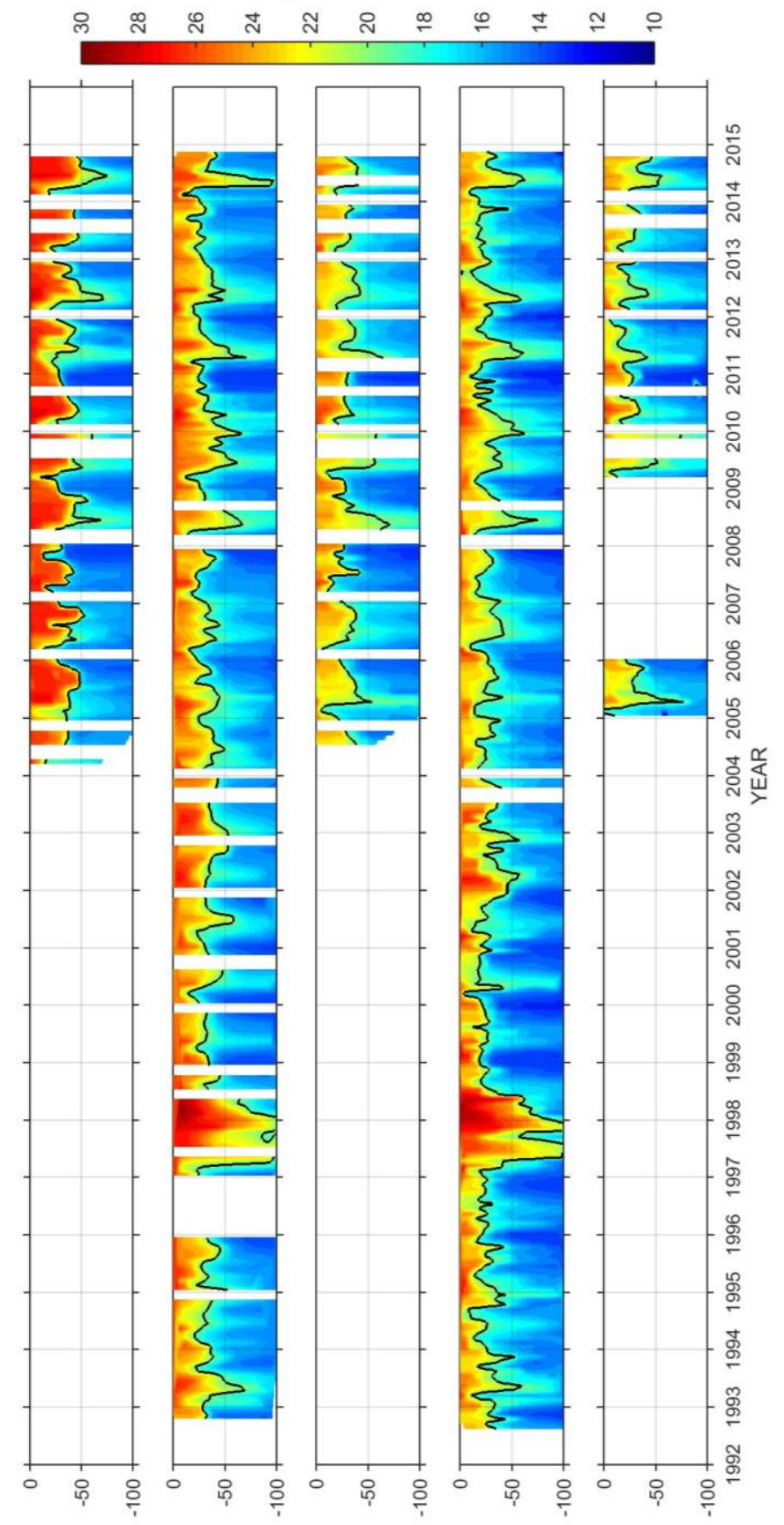

(u) पıdə0

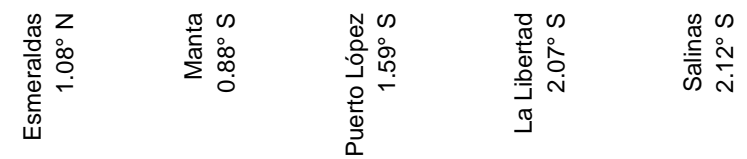

Fig. 5. Time series of sea temperature profiles from 0 to $100 \mathrm{~m}$ of depth at the 5 coastal stations. Panels are ordered by latitude with North upwards. The depth of the $20^{\circ} \mathrm{C}$ isotherm is contoured in black. 


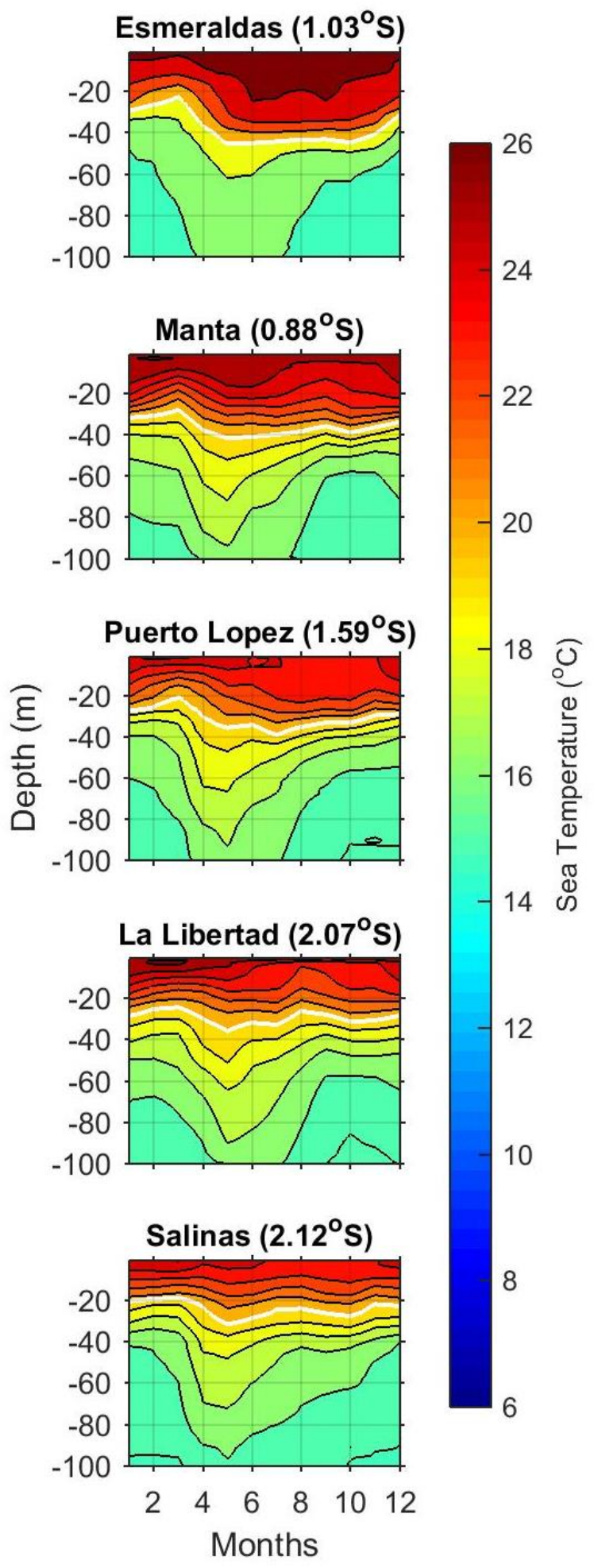

Fig. 6. Temperature profile climatology from coastal stations. Panels are ordered by latitude with North upwards. $20^{\circ} \mathrm{C}$ isotherm in white contours. 

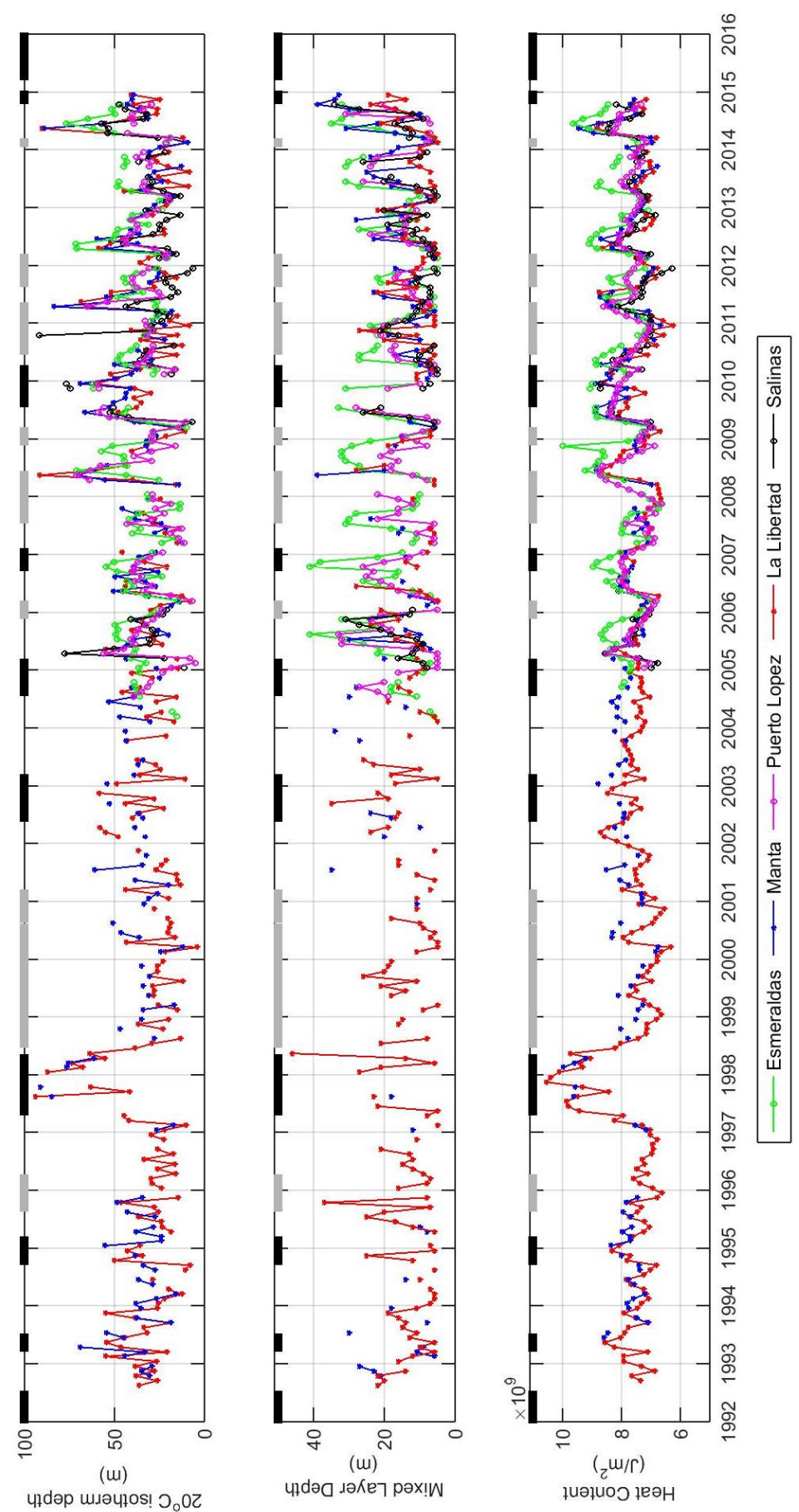

Fig. 7. Heat Content, $20^{\circ} \mathrm{C}$ isotherm depth and mixed layer depth from each coastal station. Missing data are due to profiles that do not extend to depths of $100 \mathrm{~m}$, where the MLD or $20^{\circ} \mathrm{C}$ contour is greater than $100 \mathrm{~m}$, or there is no salinity data. Black squares on top denote warm events and gray squares denote cold events, based on 3 month running mean of ERSST.v4 SST anomalies in the Niño 3.4 region. 


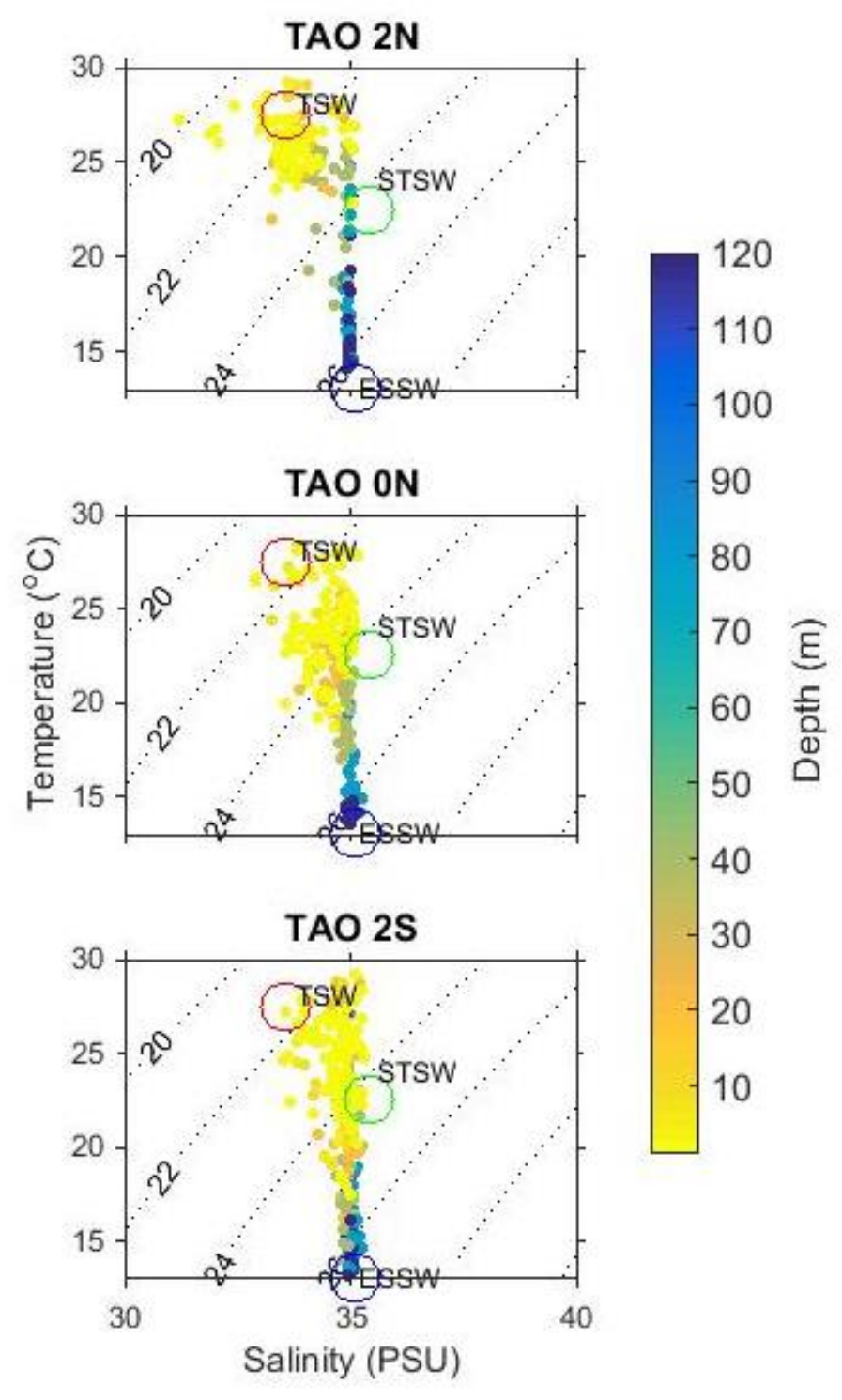

Fig. 8. T/S diagrams for the TAO buoy data. Panels are ordered by latitude with North upwards. Also shown are T/S signatures for Tropical and Subtropical Surface Waters (from Cucalón 1983). Colors represent depth (scale bar shown on the right). 


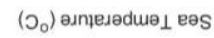

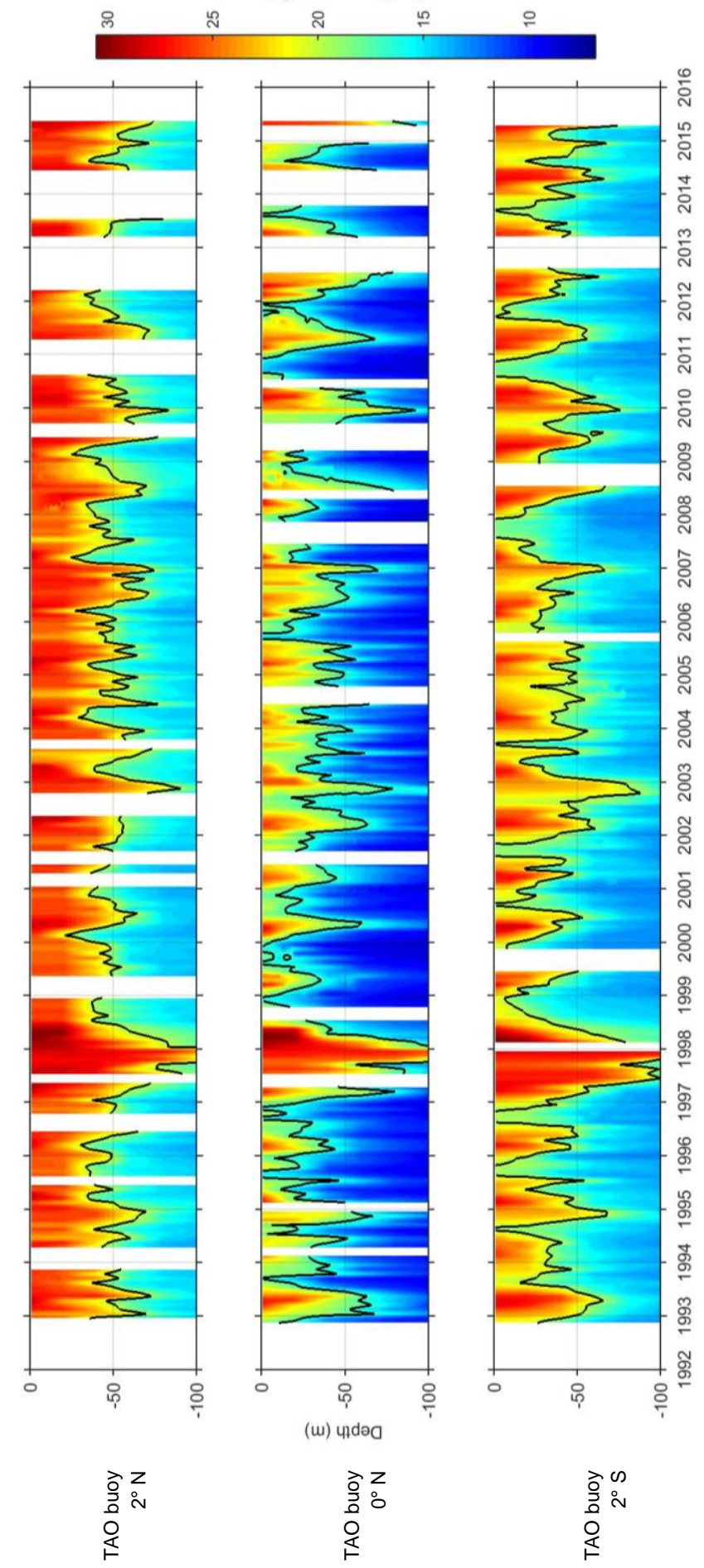

Fig. 9. Time series of sea temperature profiles from 0 to $100 \mathrm{~m}$ of depth at the 3 TAO buoys. Panels are ordered by latitude with North upwards. The depth of the $20^{\circ} \mathrm{C}$ isotherm is contoured in black. Profiles have been linearly interpolated from standard depths to an evenly spaced grid with $1 \mathrm{~m}$ resolution. 


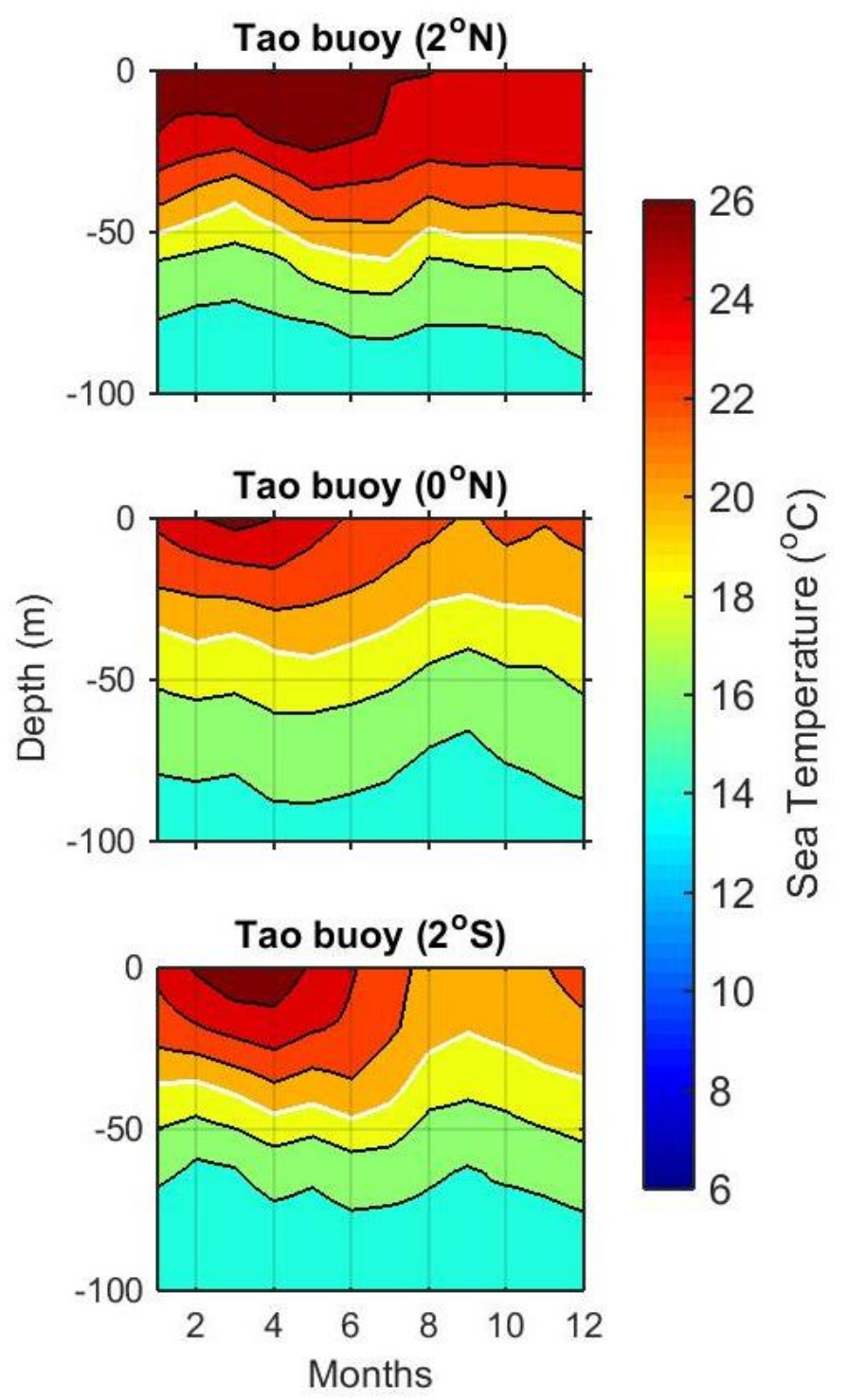

Fig. 10. Temperature profile climatology from TAO buoys. Panels are ordered by latitude with North upwards. $20^{\circ} \mathrm{C}$ isotherm in white contours. 


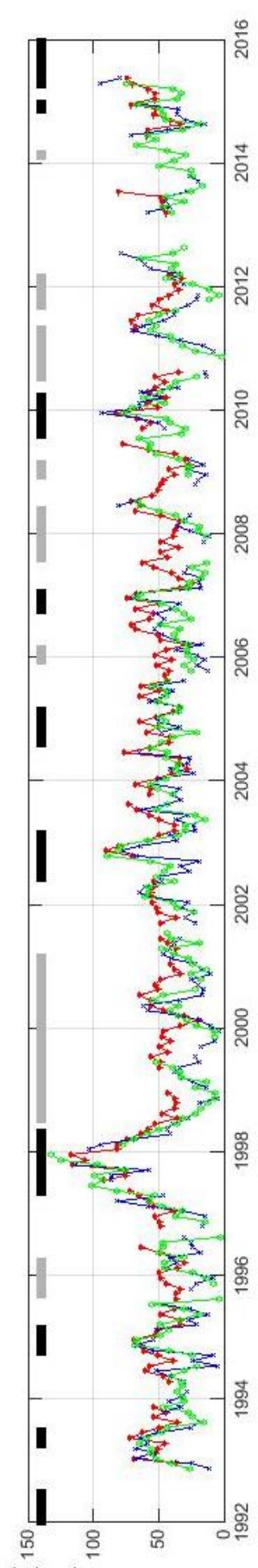

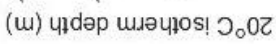
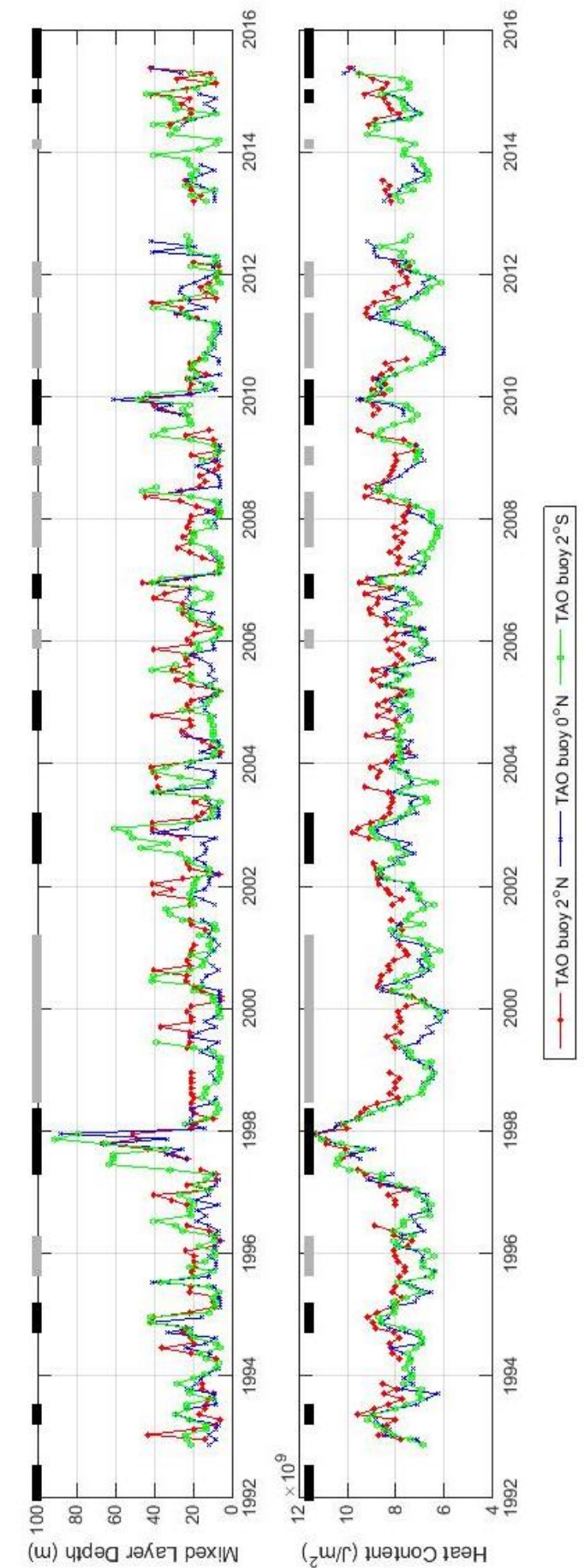

Fig. 11. Heat Content, $20^{\circ} \mathrm{C}$ isotherm depth and mixed layer depth from each TAO buoy. Missing data are due to profiles that do not extend to depths of $100 \mathrm{~m}$, where the MLD or $20^{\circ} \mathrm{C}$ contour is greater than $100 \mathrm{~m}$, or there is no salinity data. Black squares on top denote warm events and gray squares denote cold events, based on 3 month running mean of ERSST.v4 SST anomalies in the Niño 3.4 region. 

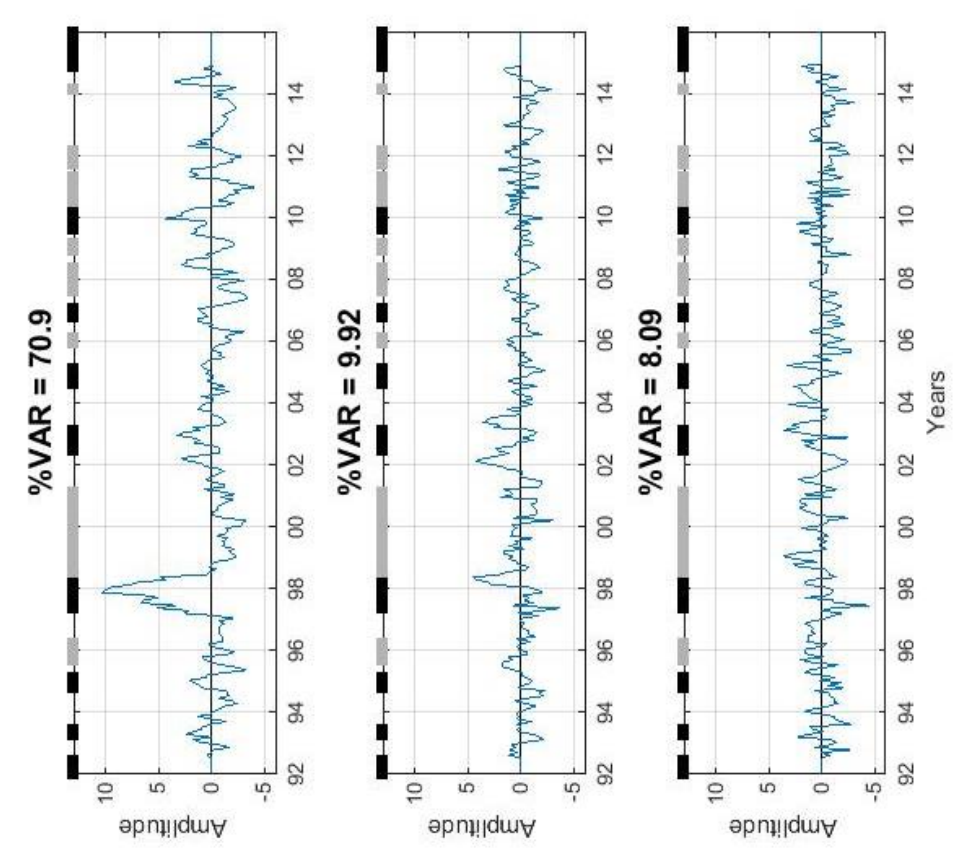

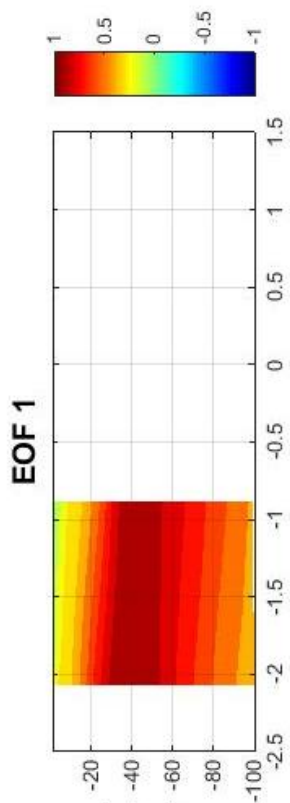

(u) पldeg
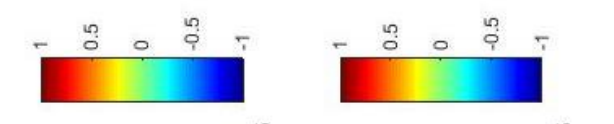

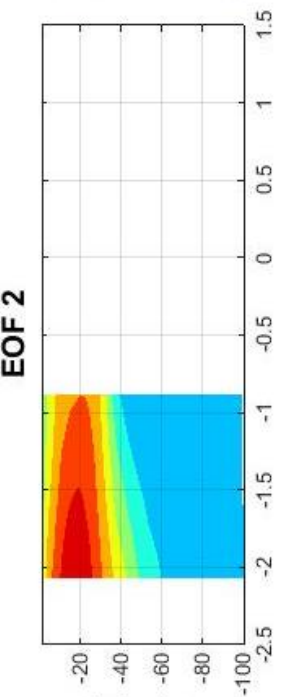

(w) पlıdə0

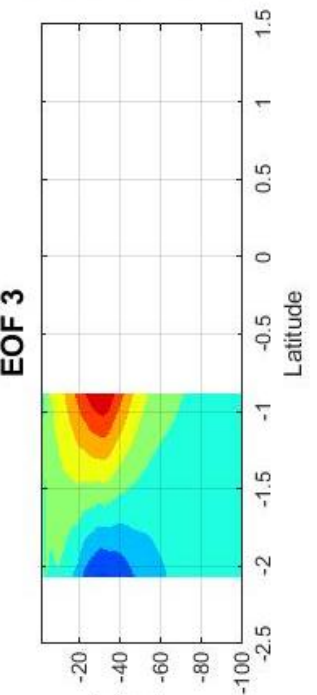

(ui) ulde0

Fig. 12. Left panels: First 3 spatial EOF modes from analysis of temperature anomaly coastal station data at La Libertad and Manta (long records). EOF's are shown as a function of depth and latitude, and are normalized to have a maximum absolute value of 1 . Right panels: The corresponding EOF amplitude time series for the first 3 modes. The amplitudes correspond to the largest temperature anomaly of each profile. The fraction of variance explained by each mode is shown on each panel. Black squares on top denote warm events and gray squares denote cold events, based on 3 month running mean of ERSST.v4 SST anomalies in the Niño 3.4 region. 

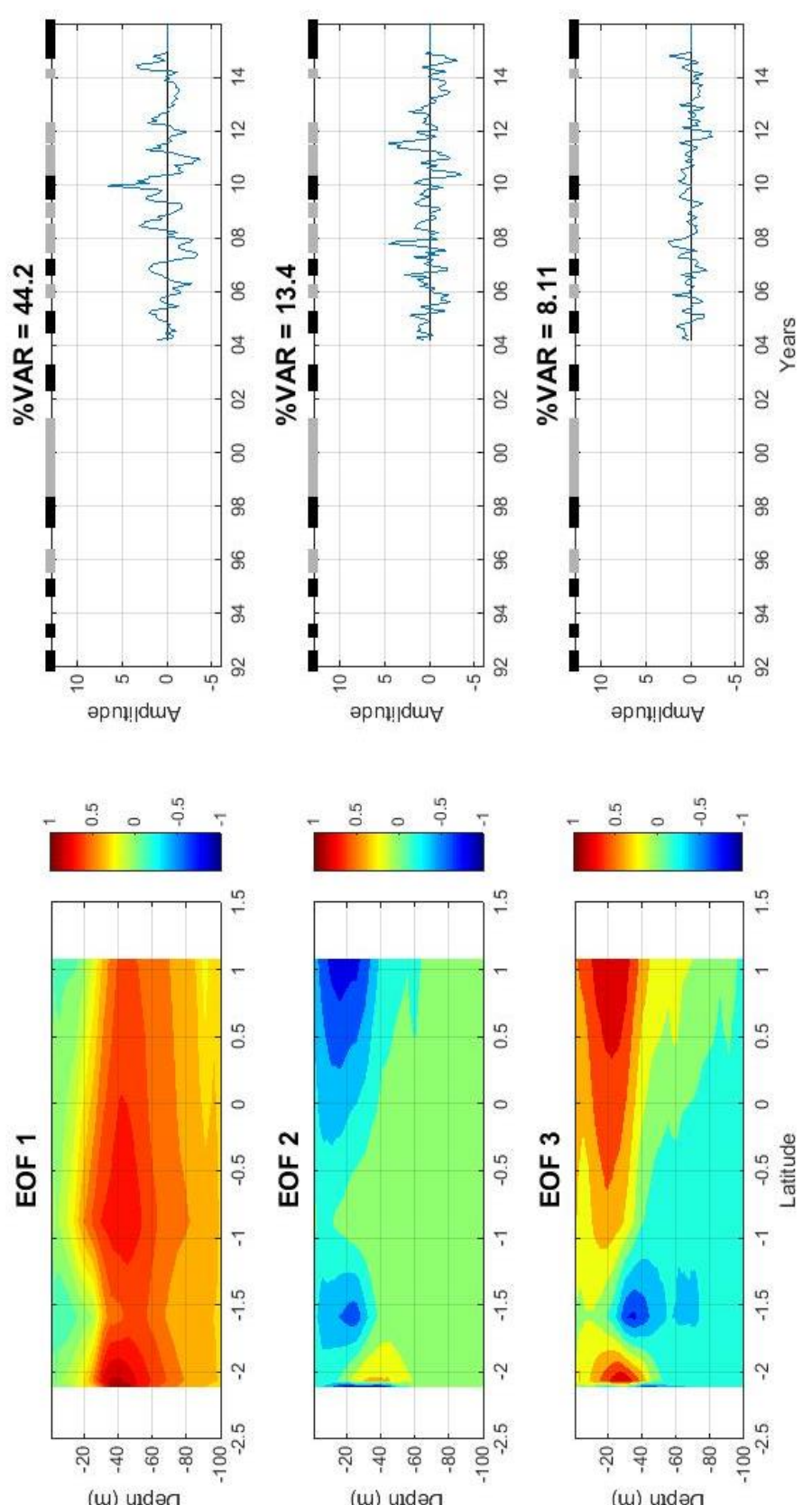

Fig. 13. Left panels: First 3 spatial EOF modes from analysis of temperature anomaly at all coastal stations data from 2004 to 2014 (length of shorter records). EOF's are shown as a function of depth and latitude, and are normalized to have a maximum absolute value of 1 .

Right panels: The corresponding EOF amplitude time series for the first 3 modes. The amplitudes correspond to the largest temperature anomaly of each profile. The fraction of variance explained by each mode is shown on each panel. Black squares on top denote warm events and gray squares denote cold events, based on 3 month running mean of ERSST.v4 SST anomalies in the Niño 3.4 region. 

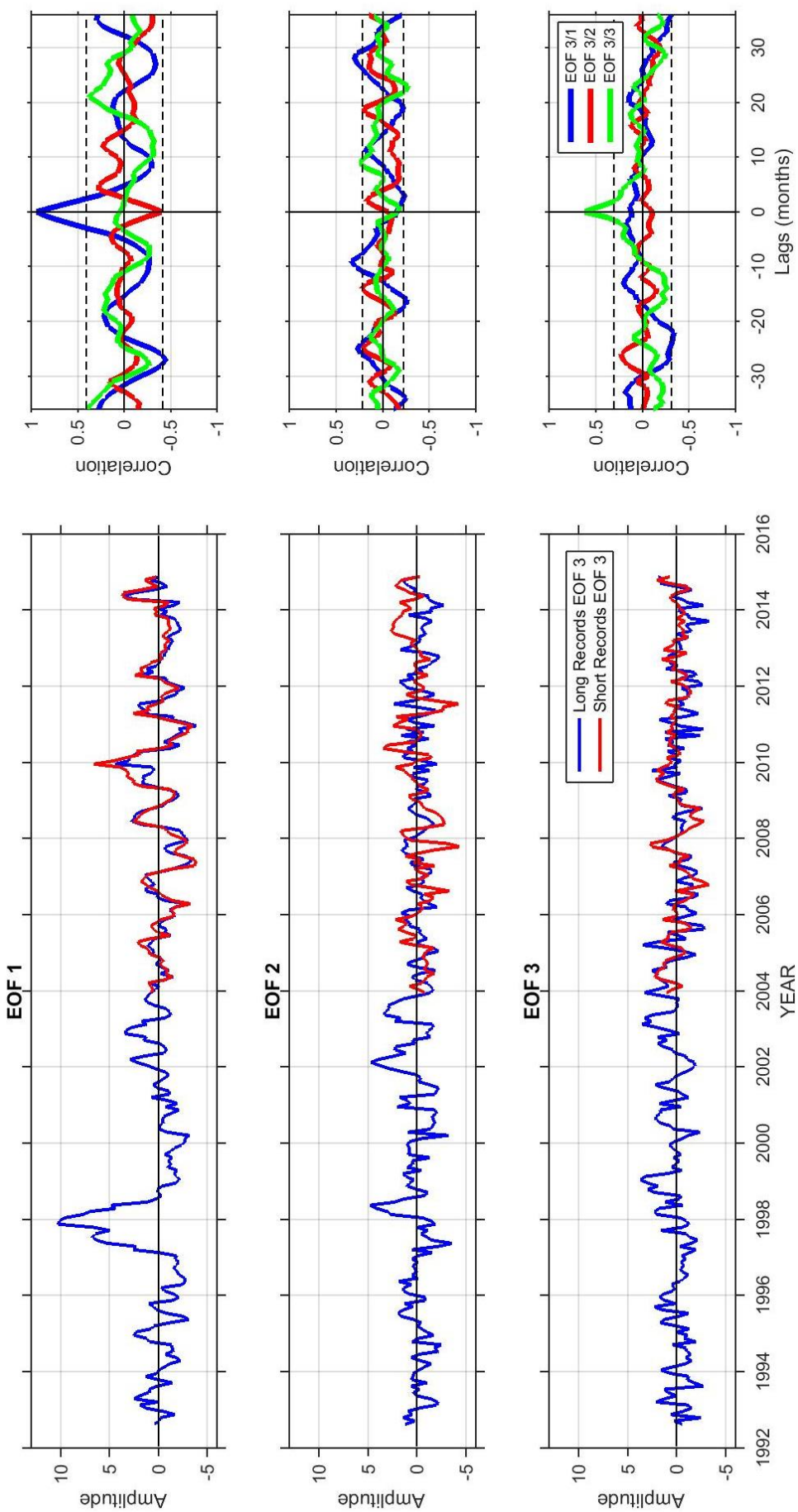

Fig. 14. Left panels: Comparison of EOF amplitude time series from the analysis of the short (red) and long (blue) records. Right panels: Cross-correlation between EOF 1, 2 and 3 from the long record analysis with EOF 1,2 and 3 from the short record analysis. 95\% confidence intervals were determined by method described in Ebisuzaki (1997). 

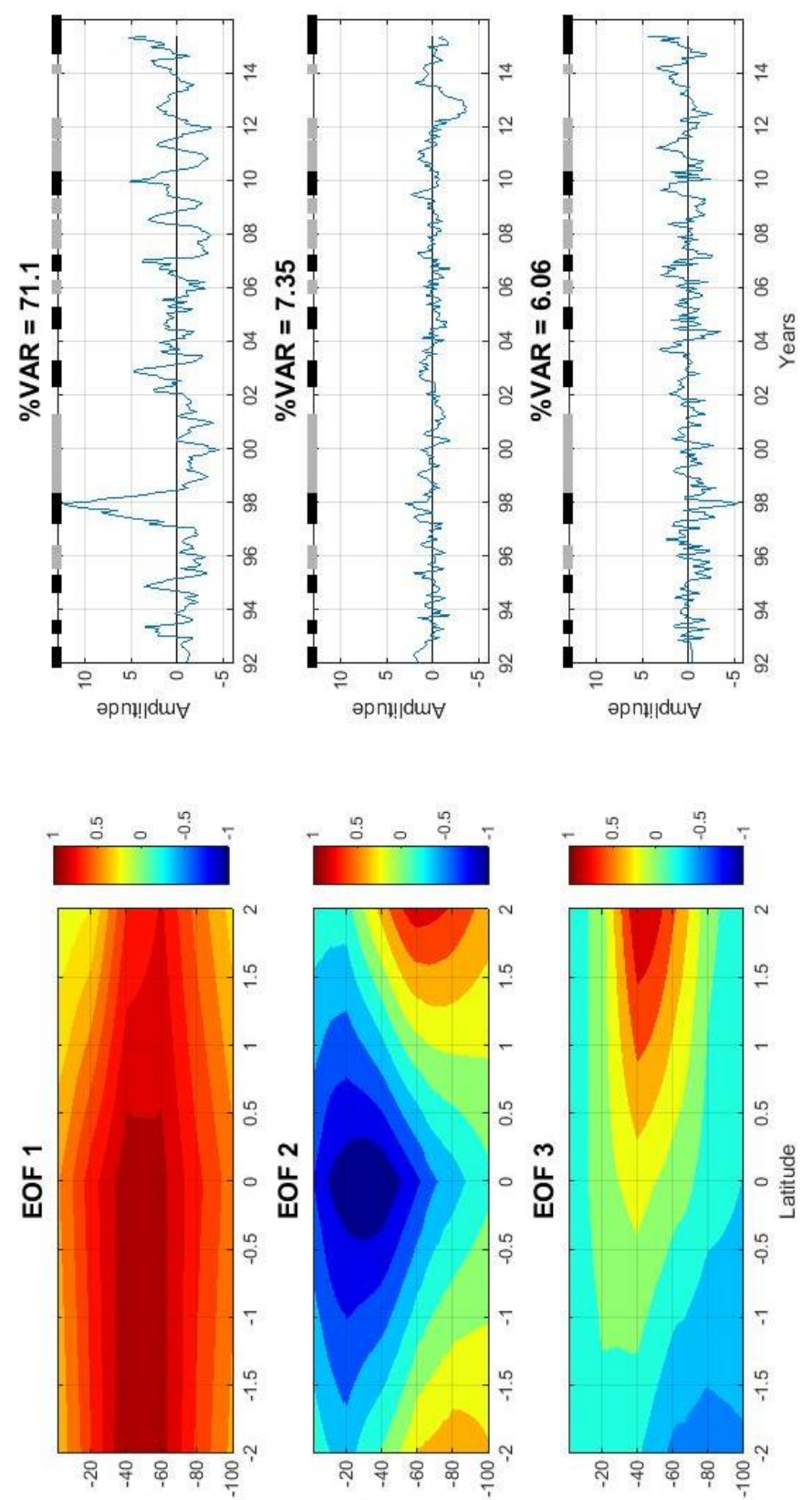

(u) yıdəa

(w) पाрdә0

(ii) पıdəa

Fig. 15. Left panels: First 3 spatial EOF modes from analysis of temperature anomaly at all TAO buoys. EOF's are shown as a function of depth and latitude, and are normalized to have a maximum absolute value of 1. Right panels: The corresponding EOF amplitude time series for the first 3 modes. The amplitudes correspond to the largest temperature anomaly of each

profile. The fraction of variance explained by each mode is shown on each panel. Black squares on top denote warm events and gray squares denote cold events, based on 3 month running mean of ERSST.v4 SST anomalies in the Niño 3.4 region. 

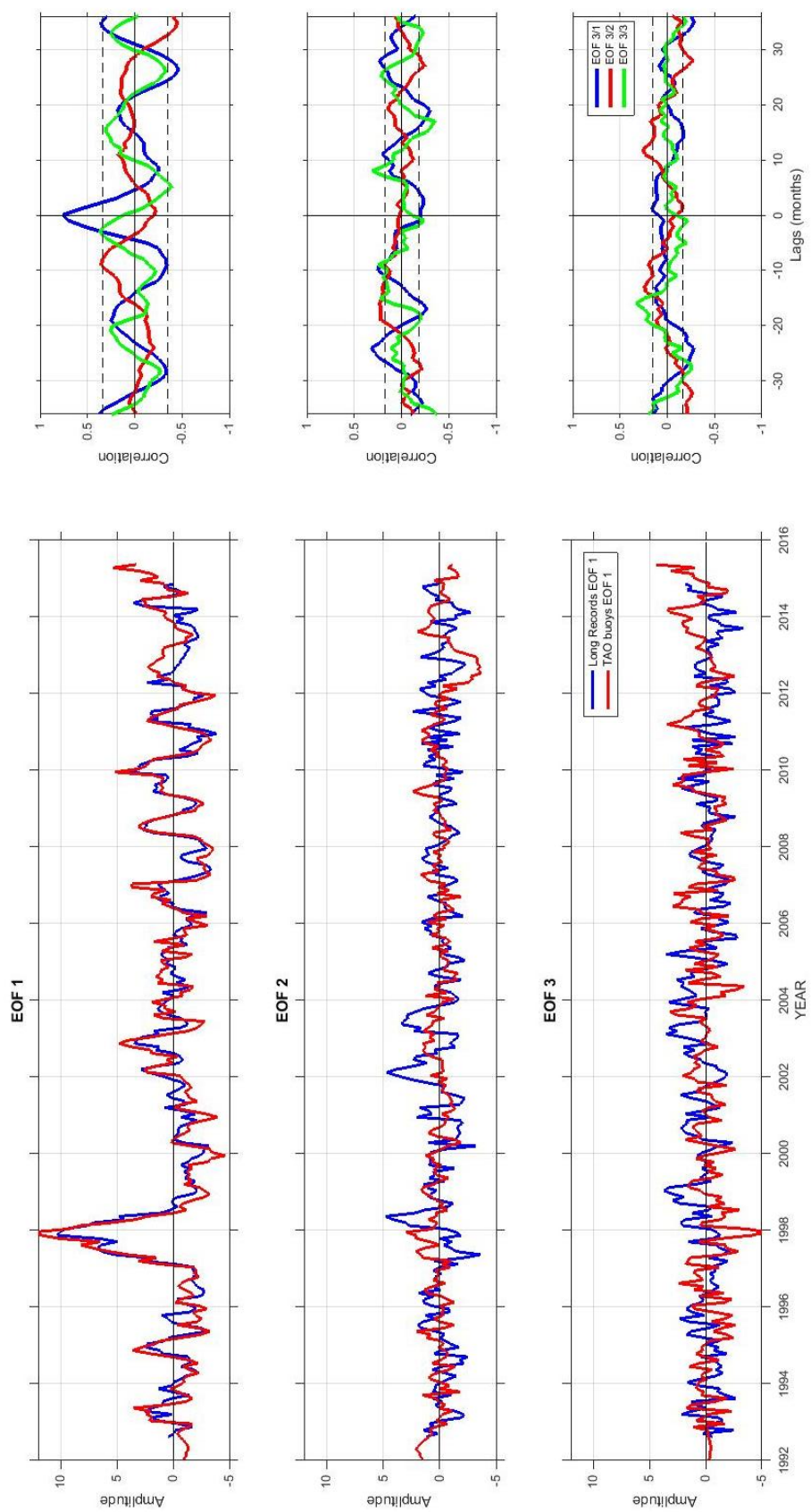

Fig. 16. Left panels: Comparison of EOF amplitude time series from the analysis of the coastal stations (long record in blue) and TAO buoy (red) data. Right panels: Crosscorrelation between EOF 1, 2 and 3 from the long record analysis with EOF 1, 2 and 3 from the TAO buoy data analysis. $95 \%$ confidence intervals were determined by method described in Ebisuzaki (1997). 


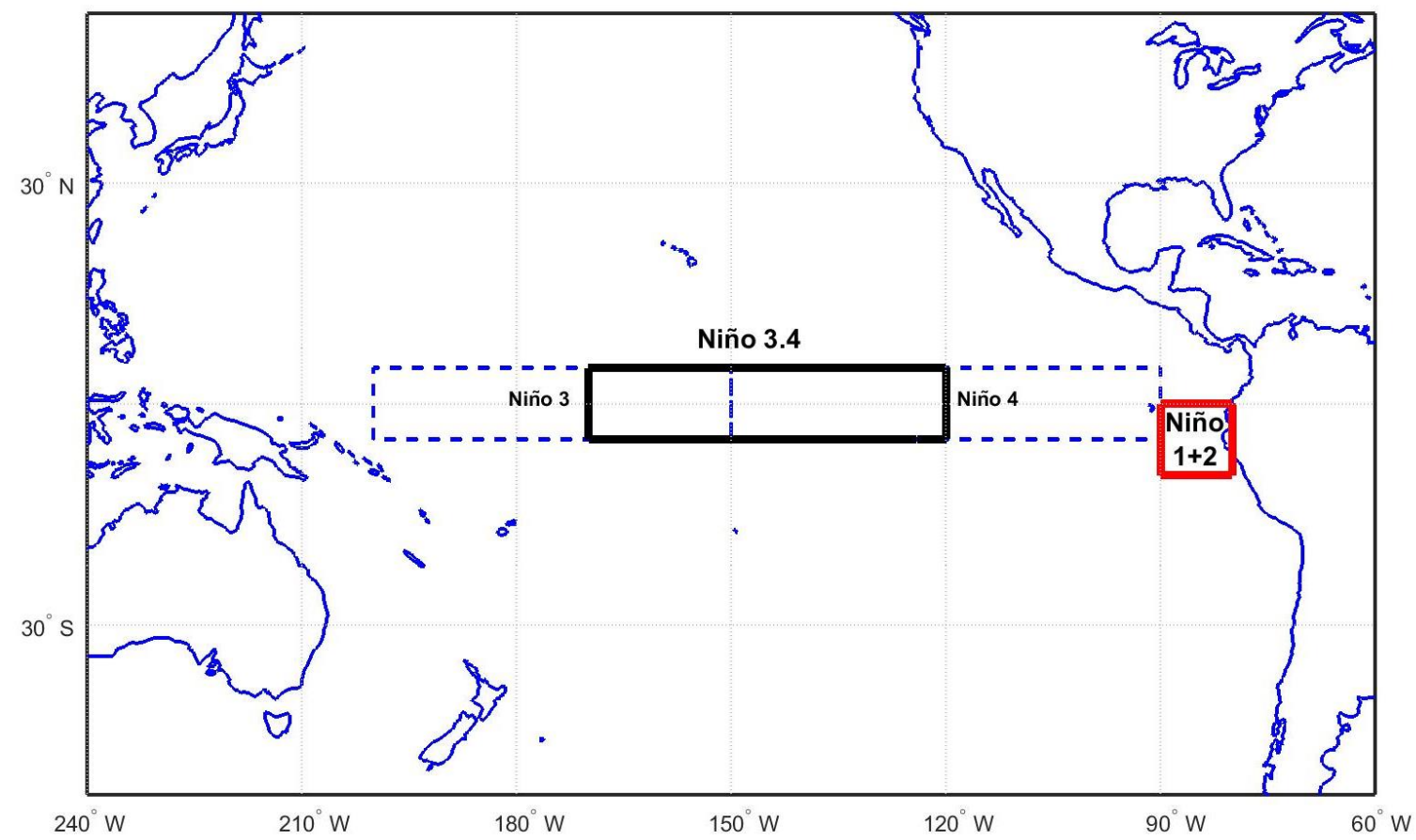

Fig. 17. Graphical depiction of the four Niño regions: Niño-1+2 $\left(0-10^{\circ} \mathrm{S}, 90^{\circ} \mathrm{W}-80^{\circ} \mathrm{W}\right)$, Niño $3\left(5^{\circ} \mathrm{N}-5^{\circ} \mathrm{S}, 150^{\circ} \mathrm{W}-90^{\circ} \mathrm{W}\right)$, Niño $4\left(5^{\circ} \mathrm{N}-5^{\circ} \mathrm{S}, 160^{\circ} \mathrm{E}-150^{\circ} \mathrm{W}\right)$ and Niño $-3.4\left(5^{\circ}\right.$ $\left.\mathrm{N}-5^{\circ} \mathrm{S}, 170^{\circ} \mathrm{W}-120^{\circ} \mathrm{W}\right)$. [Rasmusson and Carpenter, 1982]. 


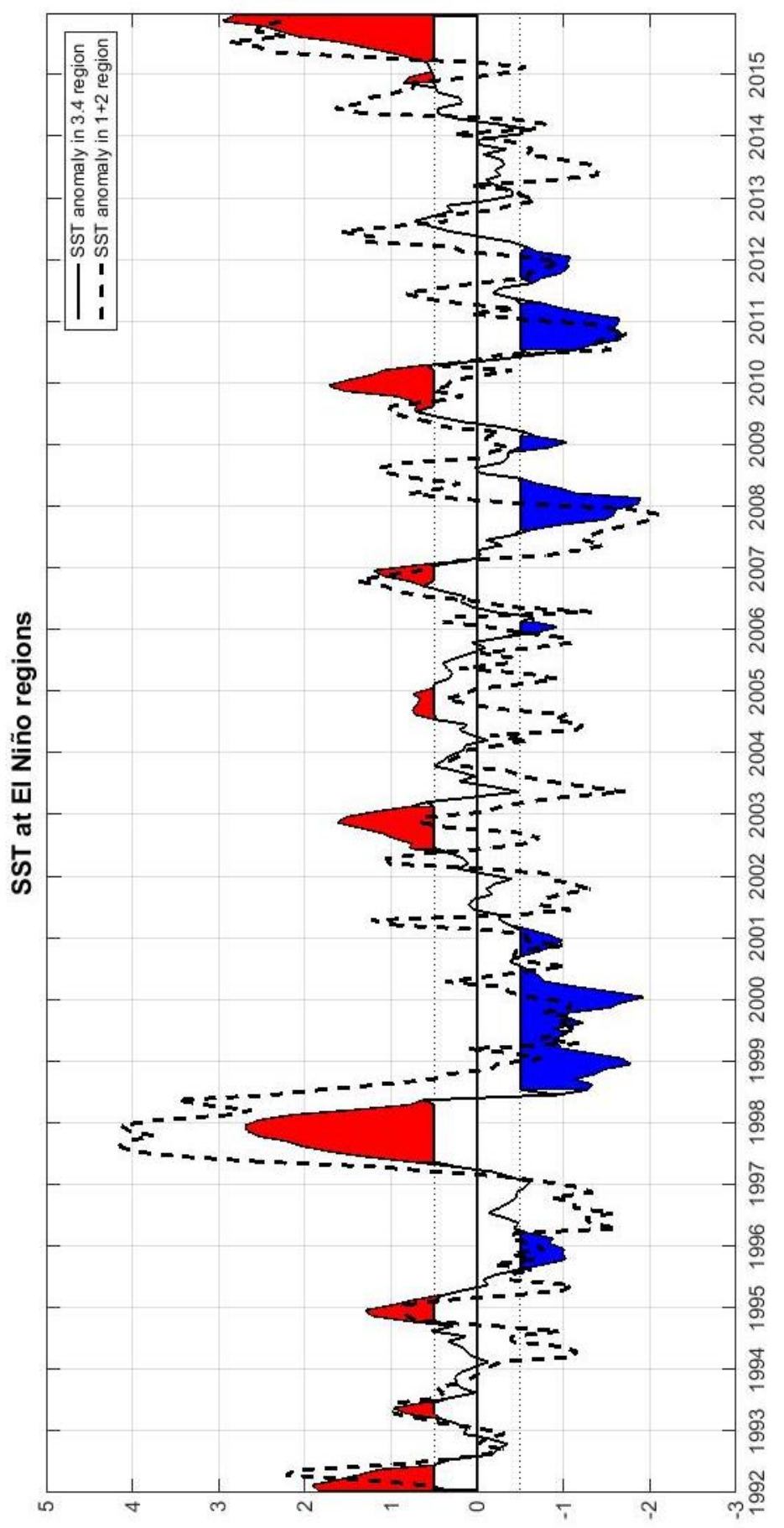

Fig. 18. Time series of ENSO $1+2$ and 3.4 regions from ERSST.v4 SST anomalies in the Niño 3.4 region $\left(5^{\circ} \mathrm{N}-5^{\circ} \mathrm{S}, 120^{\circ}-170^{\circ} \mathrm{W}\right)$ and Niño $1+2\left(0-10^{\circ} \mathrm{S}, 90^{\circ} \mathrm{W}-80^{\circ} \mathrm{W}\right)$ [Huang et al., 2015]. 

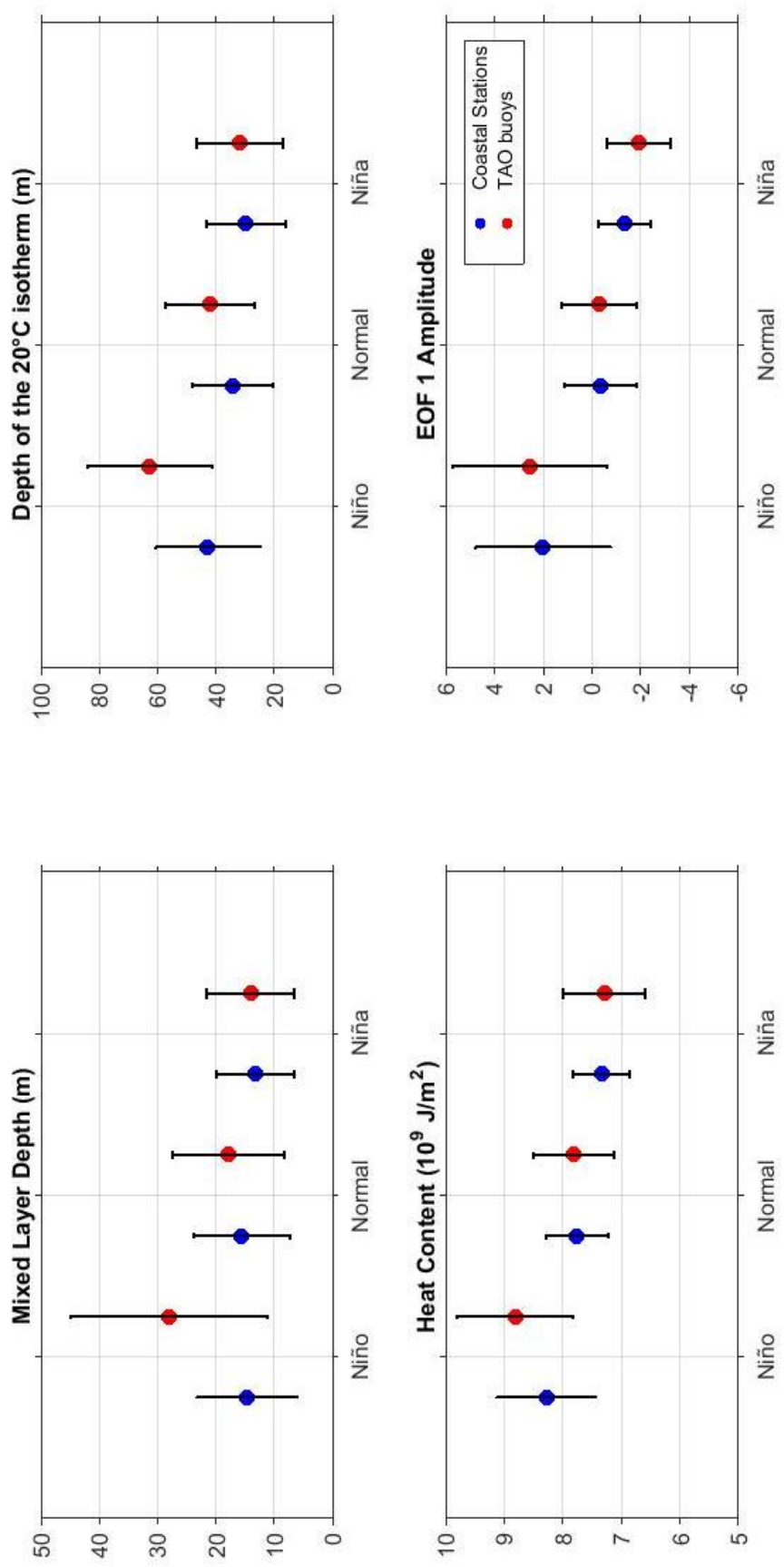

Fig. 19. Top panels: Mixed layer depth and depth of the $20^{\circ} \mathrm{C}$ isotherm at the coastal stations (blue) and TAO buoys (red) separated by Niño (warm), normal and Niña (cold) events. Error bars are calculated from one standard deviation. Lower panels: Heat Content and Amplitude of the First EOF mode at the coastal stations (blue) and TAO buoys (red). Error bars are calculated from one standard deviation separated by Niño (warm), normal and Niña (cold) events. 

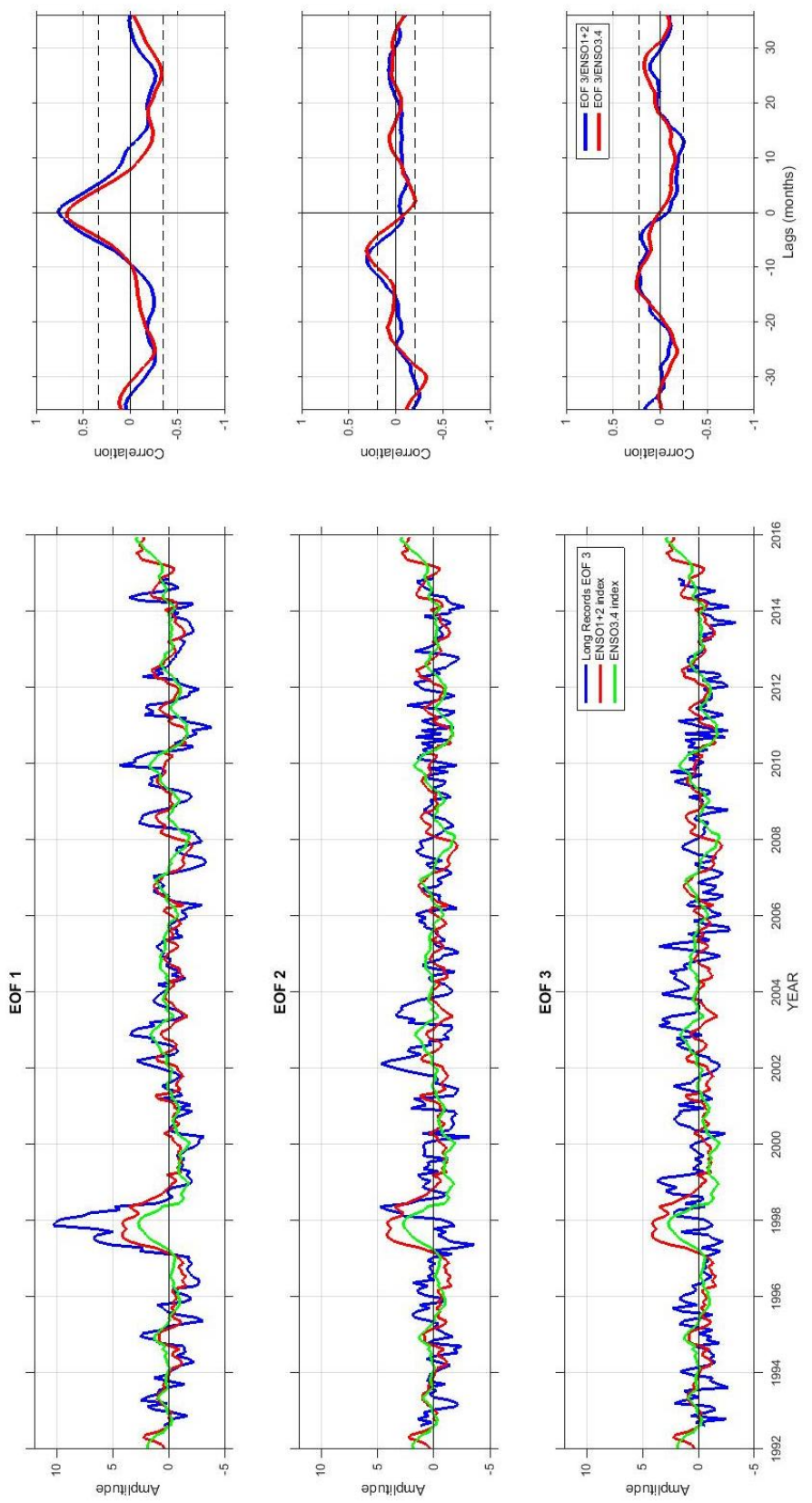

Fig. 20. Left panels: Comparison of EOF amplitude time series from analysis of anomaly coastal station data (long record in blue) with ENSO 1+2 (red) and ENSO 3.4 (green) indices.

Right panels: Cross-correlations between coastal station amplitude EOF time series and ENSO 1+2 (blue) and 3.4 (red) indices. 95\% confidence intervals were determined by method described in Ebisuzaki (1997). 

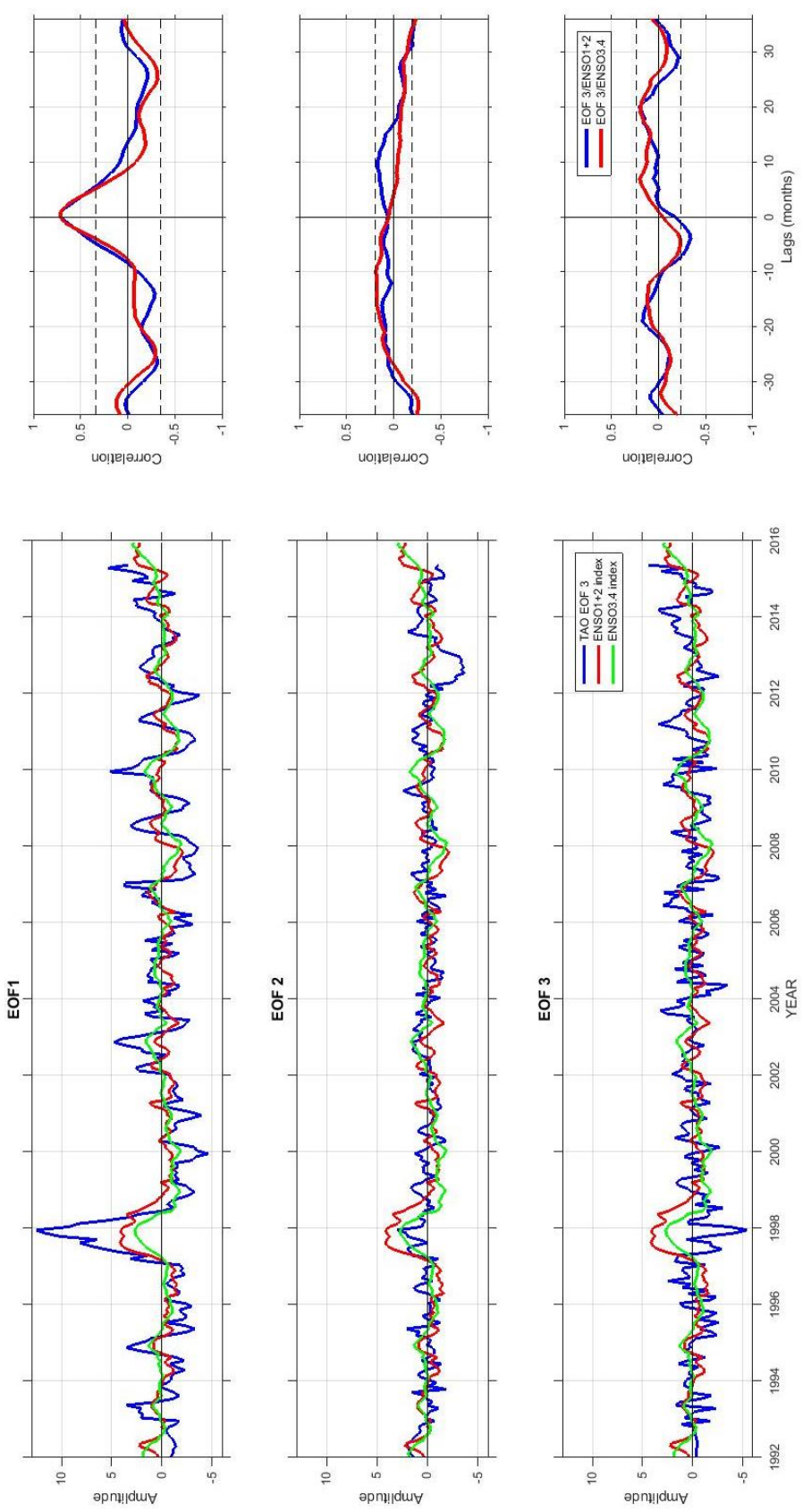

Fig. 21. Left panels: Comparison of EOF amplitude time series from analysis of anomaly TAO buoy data (blue) with ENSO 1+2 (red) and ENSO 3.4 (green) indices. Right panels: Cross-correlations between coastal station amplitude EOF time series and ENSO 1+2 (blue) and 3.4 (red) indices. 95\% confidence intervals were determined by method described in Ebisuzaki (1997). 


\section{Maximum Correlations in $\mathrm{U}$ direction}
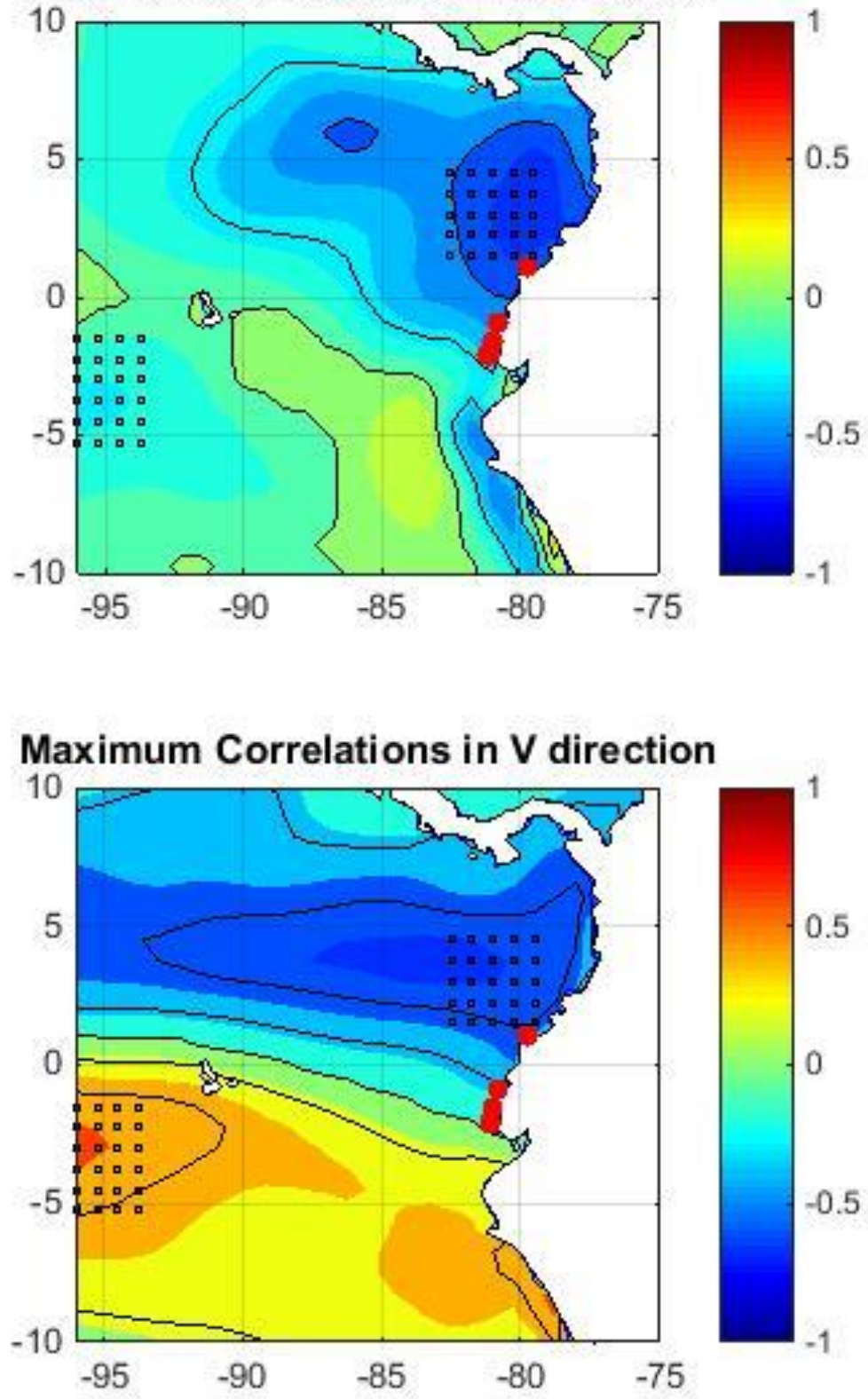

Fig. 22. Cross-correlation between the coastal stations' first EOF mode and monthly averaged U (top panel) and V (lower panel) Winds obtained from ERA-Interim Reanalysis. Black squares denote the areas with largest (positive or negative) correlation, taken for EOF analysis. 


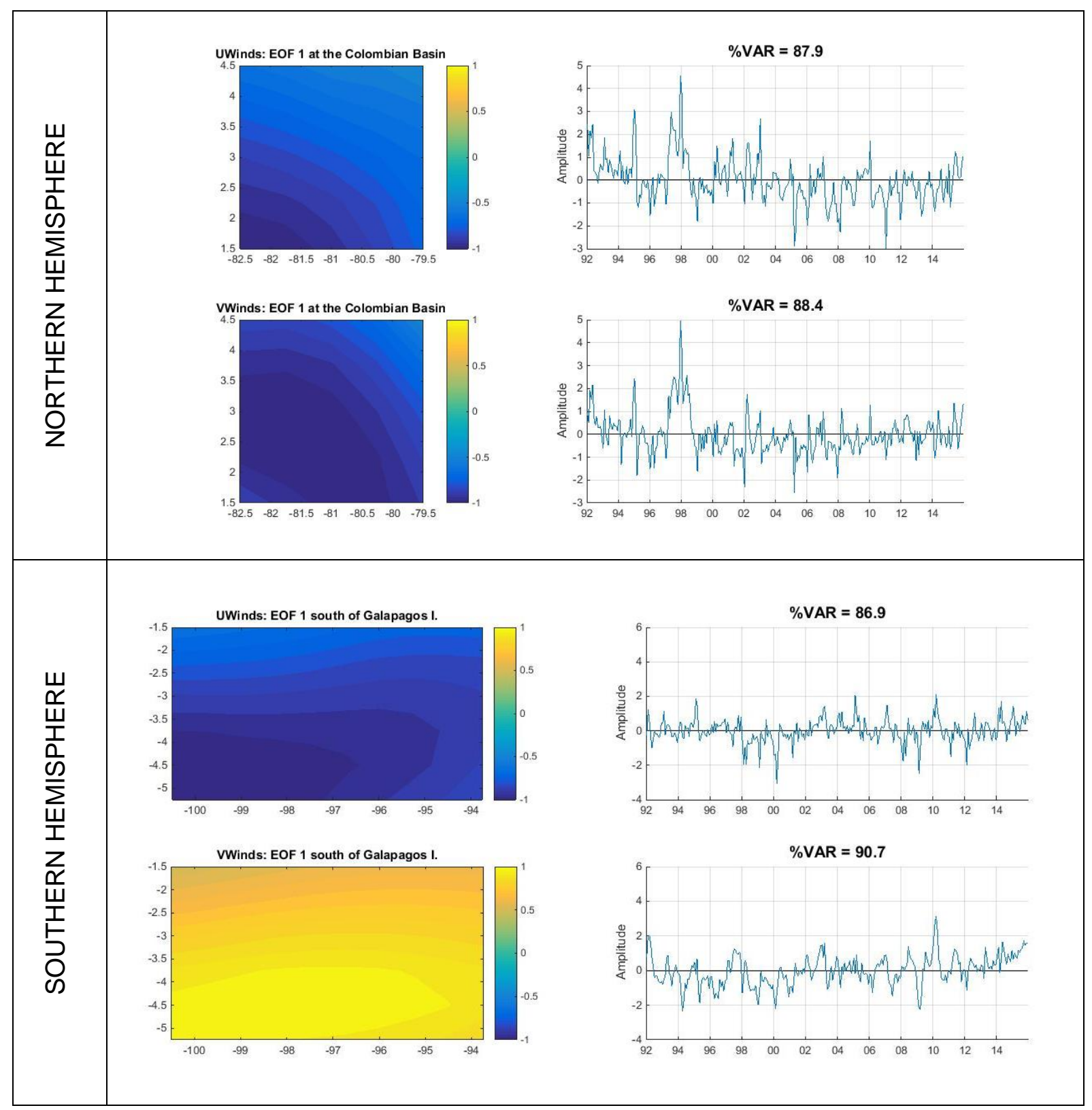

Fig. 23. Left panels: First spatial EOF modes from analysis of Wind anomaly in the Colombian Basin and south of the Galápagos Islands (areas shown in Fig. 21). EOF's are shown as a function of longitude and latitude, and are normalized to have a maximum absolute value of 1. Right panels: The corresponding EOF amplitude time series for the first EOF mode of Wind anomaly at the same area. The amplitudes correspond to the largest wind anomaly of each location. The fraction of variance explained by each mode is shown on each panel. Top (bottom) panels correspond to $U(\mathrm{~V})$ component of the wind. 

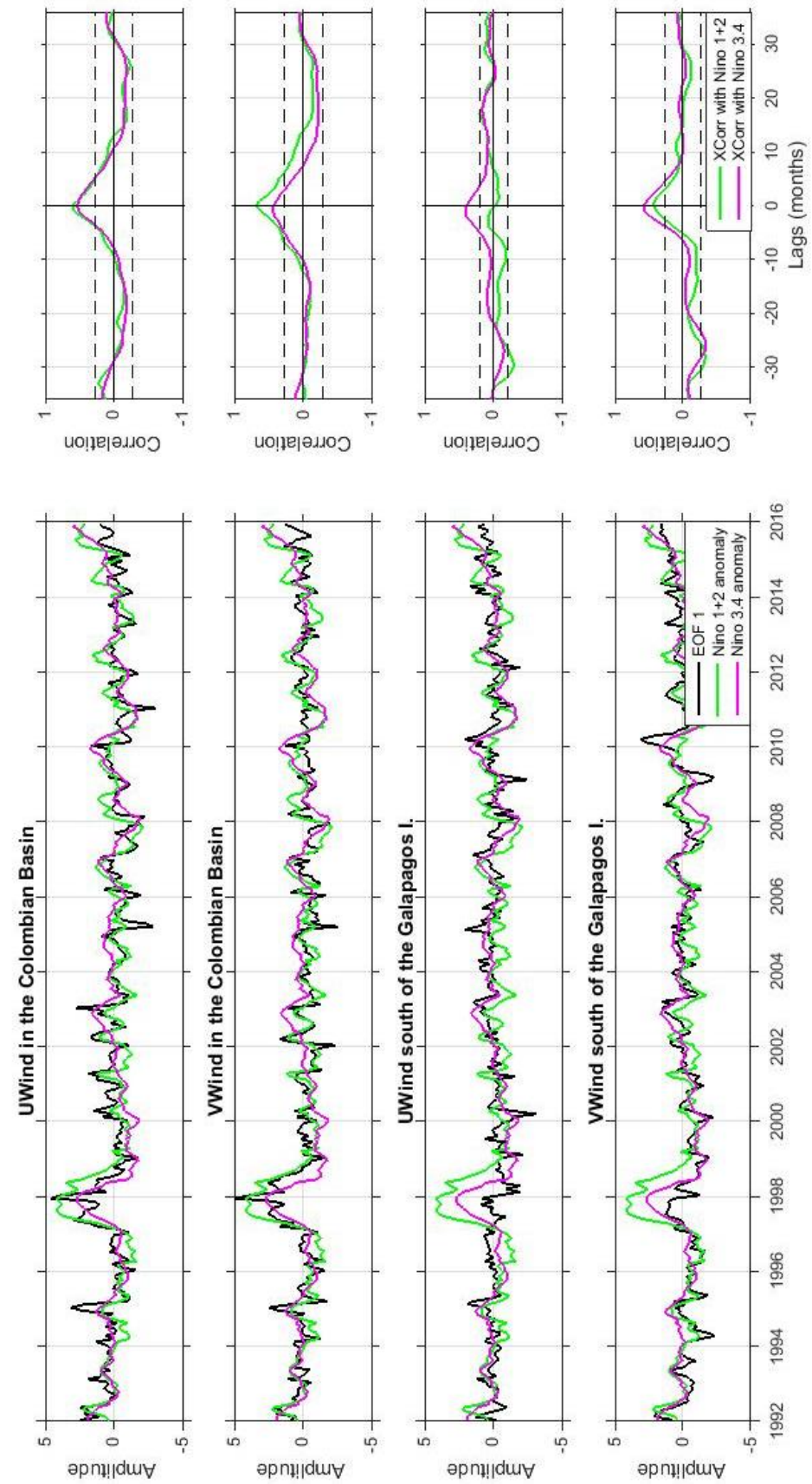

Fig. 24. Left panels: Comparison of EOF amplitude time series from analysis of anomaly $U$ and $\mathrm{V}$ winds at the Colombian Basin and south of the Galápagos Islands (black) with ENSO $1+2$ (green) and ENSO 3.4 (magenta) indices. Right panels: Cross-correlations between the first mode of wind EOF time series and ENSO 1+2 (green) and 3.4 (magenta) indices. 95\% confidence intervals were determined by method described in Ebisuzaki (1997). 